\title{
Korean Medication Algorithm for Depressive Disorders 2017: Third Revision
}

\author{
Jeong Seok Seo ${ }^{1}$, Won-Myong Bahk ${ }^{2}$, Hee Ryung Wang ${ }^{2}$, Young Sup Woo' ${ }^{2}$ Young-Min Park ${ }^{3}$, \\ Jong-Hyun Jeong, ${ }^{2}$, Won Kim ${ }^{4,5}$, Se-Hoon Shim ${ }^{6}$, Jung Goo Lee, ${ }^{7,}$, Duk-In Jon ${ }^{9}$, Kyung Joon Min ${ }^{10}$ \\ ${ }^{1}$ Department of Psychiatry, Konkuk University School of Medicine, Cheongju, ${ }^{2}$ Department of Psychiatry, College of Medicine, The Catholic \\ University of Korea, Seoul, ${ }^{3}$ Department of Psychiatry, Ilsan Paik Hospital, Inje University College of Medicine, Goyang, ${ }^{4}$ Department of \\ Psychiatry, Seoul Paik Hospital, Inje University College of Medicine, Seoul, ${ }^{5}$ Korea/Stress Research Institute, Inje University, Seoul, ${ }^{6}$ Department \\ of Psychiatry, Soonchunhyang University Cheonan Hospital, Soonchunhyang University College of Medicine, Cheonan, ${ }^{7}$ Department of \\ Psychiatry, Inje University Haeundae Paik Hospital, Inje University College of Medicine, Busan, ${ }^{8}$ Paik Institute for Clinical Research, Department \\ of Health Science and Technology, Graduate School of Inje University, Busan, ${ }^{9}$ Department of Psychiatry, Hallym University Sacred Heart \\ Hospital, Hallym University College of Medicine, Anyang, ${ }^{10}$ Department of Psychiatry, Chung-Ang University College of Medicine, Seoul, Korea
}

\begin{abstract}
Objective: In 2002, the Korean Society for Affective Disorders developed the guidelines for the treatment of major depressive disorder (MDD), and revised it in 2006 and 2012. The third revision of these guidelines was undertaken to reflect advances in the field.

Methods: Using a 44-item questionnaire, an expert consensus was obtained on pharmacological treatment strategies for MDD 1) without or 2) with psychotic features, 3) depression subtypes, 4) maintenance, 5) special populations, 6) the choice of an antidepressant (AD) regarding safety and adverse effects, and 7) non-pharmacological biological therapies. Recommended first, second, and third-line strategies were derived statistically.

Results: AD monotherapy is recommended as the first-line strategy for non-psychotic depression in adults, children/adolescents, elderly adults, patient with persistent depressive disorder, and pregnant women or patients with postpartum depression or premenstrual dysphoric disorder. The combination of AD and atypical antipsychotics (AAP) was recommended for psychotic depression in adult, child/adolescent, postpartum depression, and mixed features or anxious distress. Most experts recommended stopping the ongoing initial AD and AAP after a certain period in patients with one or two depressive episodes. As an MDD treatment modality, 92\% of experts are considering electroconvulsive therapy and $46.8 \%$ are applying it clinically, while $86 \%$ of experts are considering repetitive transcranial magnetic stimulation but only $31.6 \%$ are applying it clinically.

Conclusion: The pharmacological treatment strategy in 2017 is similar to that of Korean Medication Algorithm for Depressive Disorder 2012. The preference of AAPs was more increased.
\end{abstract}

KEY WORDS: Algorithms; Depressive disorder; Drug therapy; Guideline.

\section{INTRODUCTION}

The purpose of the clinical guideline is to assist clinicians' decisions on proper treatment options and to im-

Received: July 12, 2017 / Accepted: August 1, 2017

Address for correspondence: Won-Myong Bahk, MD, PhD

Department of Psychiatry, Yeouido St. Mary's Hospital, College of

Medicine, The Catholic University of Korea, 10 63-ro,

Youngdeungpo-gu, Seoul 07345, Korea

Tel: +82-2-3779-1051, Fax: +82-2-780-6577

E-mail: wmbahk@catholic.ac.kr

Kyung Joon Min, MD, PhD

Department of Psychiatry, Chung-Ang University College of Medicine, 102 Heukseok-ro, Dongjak-gu, Seoul 06973, Korea

Tel: +82-2-6299-1521, Fax: +82-2-6298-1508

E-mail: kjoonmin@gmail.com prove the quality of medication treatments in danger of bias from overwhelming research informations. ${ }^{1)}$

Depressive disorder is a heterogeneous and complex disorder that has various symptoms, clinical courses and outcome including treatment response to pharmacotherapy, or to non-pharmacological somatic therapy, ${ }^{2)}$ and that is related with cognitive and occupational function, quality of life, suicide and socioeconomic burden. ${ }^{3)}$

For the purpose of clinical guideline, therefore, the Korean Medication Algorithm Project for Depressive Disorder that is a task force within the Korean Society for Affective Disorders (KSAD), one of the 23 nonprofit scientific and educational psychiatrists' societies under the

(c) This is an Open-Access article distributed under the terms of the Creative Commons Attribution Non-Commercial License (http://creativecommons.org/licenses/by-nc/4.0) which permits unrestricted non-commercial use, distribution, and reproduction in any medium, provided the original work is properly cited. 
Korean Neuropsychiatric Association, developed the Korean Medication Algorithm for Major Depressive Disorder in 2002 (KMAP-MD 2002), ${ }^{4)}$ and conducted first revision in 2006 (The Korean Medication Algorithm for Depressive Disorder, KMAP-DD 2006), ${ }^{5)}$ second revision in 2012 (KMAP-DD 2012), ${ }^{2)}$ and this third revision of KMAP-DD in 2017.

The KMAP-DD series contain seven sections giving pharmacological treatment strategies for 1) major depressive disorder (MDD) without psychotic features, 2) MDD with psychotic features, 3) dysthymia and other depressive disorder subtypes, 4) maintenance treatment, 5) treatment strategies for special populations, 6) the choice of an $\mathrm{AD}$ in the context of safety, adverse effects and comorbid physical illnesses, and 7) non-pharmacological biological therapies. An exception is KMAP-MD 2002, which contains few newer antidepressants (AD) and atypical antipsychotics (AAP) and has a different methodology compared with later KMAP-DDs. The KMAP-DD 2006, 2012, and 2017 series is the expert's consensus guideline, with current evidence on treatment of depressive disorder evaluated by a KMAP executive committee, consisting of 12 well-trained psychiatrists with extensive clinical expe- rience in the field of mood disorders in Korea. In this revision, there is a few modifications to the questionnaire (Table 1). For example, because of the introduction of the Diagnostic and Statistical Manual of Mental Disorders 5th edition (DSM-5) in 2013, the specifiers "mixed features" and "anxious distress" were included in "subtype" section $C$ in this revision to enable comparisons of clinical pharmacological treatment before and after 2013.

We summarized the results of third revision of Korean experts' opinions on the pharmacological treatment of patients with depressive disorder and compared the results between the KMAP series.

\section{METHODS}

The overall study design and method of previous revisions were retained in this revision. To obtain the experts' consensus, we composed a review committee and the review committee completed the modified questionnaire. The data were statistically analyzed.

\section{Review Committee}

The composition criteria for the review committee were

Table 1. Comparison among first (2006), second (2012), and third (2017) revisions of the Korean Medication Algorithm for Depressive Disorder

\begin{tabular}{|c|c|c|c|}
\hline & First revision in 2006 & Second revision in 2012 & Third revision in 2017 \\
\hline Depressive episode & $\begin{array}{l}\text { Mild } \\
\text { Moderate } \\
\text { Non-psychotic severe } \\
\text { Psychotic severe }\end{array}$ & $\begin{array}{l}\text { Mild to moderate } \\
\text { Non-psychotic severe } \\
\text { Psychotic severe }\end{array}$ & Same as 2012 \\
\hline $\begin{array}{l}\text { AD dosage and duration } \\
\text { of treatment }\end{array}$ & Present & Deletion & $\begin{array}{l}\text { Change: duration of initial treatment and } \\
\text { number of choosing } \mathrm{AD} \text { as initial treatment }\end{array}$ \\
\hline Subtype & $\begin{array}{l}\text { Dysthymia } \\
\text { Minor depressive disorder } \\
\text { Atypical features } \\
\text { Melancholic features }\end{array}$ & $\begin{array}{l}\text { Dysthymia } \\
\text { Minor depressive disorder } \\
\text { Atypical features } \\
\text { Melancholic features } \\
\text { Seasonal pattern }\end{array}$ & $\begin{array}{l}\text { Dysthymia } \\
\text { Minor depressive disorder } \\
\text { Atypical features } \\
\text { Melancholic features } \\
\text { Seasonal pattern } \\
\text { Mixed features } \\
\text { Anxious distress }\end{array}$ \\
\hline Comorbid physical illness & Absent & Newly added & Same as 2012 \\
\hline Special population & Child only & $\begin{array}{l}\text { Child and adolescent } \\
\text { Elderly } \\
\text { Women }\end{array}$ & Same as 2012 \\
\hline $\begin{array}{l}\text { Non-pharmacological } \\
\text { biological therapy }\end{array}$ & ECT only & $\begin{array}{l}\text { Including TMS, phototherapy, } \\
\text { nutritional therapy, sleep deprivation, } \\
\text { VNS, DBS as well as ECT }\end{array}$ & Same as 2012 \\
\hline $\begin{array}{l}\text { Response rate of review } \\
\text { committee }\end{array}$ & $66.3 \%(67 / 101)$ & $54.5 \%(67 / 123)$ & $54.9 \%(79 / 144)$ \\
\hline
\end{tabular}

$\mathrm{AD}$, antidepressant; $\mathrm{ECT}$, electroconvulsive therapy; TMS, transcranial magnetic stimulation; VNS, vagal nerve stimulation; DBS, deep brain stimulation. 
the same as those of KMAP-DD 2012. We recruited 144 Korean psychiatrists who were life-long members of KSAD, had more than 15 years of clinical experience in the field of mood disorders, and who had each published at least one paper related to mood disorders during the previous year. Members worked in a wide variety of clinical settings (university hospitals, $n=97$; general and mental hospitals, $n=34$; private psychiatric clinics, $n=13$ ). All members of the review committee provided written informed consent for their participation in this survey. Of the 144 psychiatrists, 79 (54.9\%) responded to our survey. Respondents received a predetermined fee for their participation.

\section{Questionnaire}

The KMAP-DD third-revision questionnaire was a modification of the instrument used for the KMAP-DD 2012 guidelines. ${ }^{2)}$ The questionnaire included 7 sections and 44 general categories organized into 117 sub-items that offered 876 options. These were organized into the following sections: 1) MDD without psychotic features; 2) MDD with psychotic features; 3 ) persistent depressive disorder (dysthymia) and treatment for other clinical subtypes (melancholic features, atypical features, seasonal pattern, mixed features, anxious distress, and minor depressive disorder); 4) strategies for maintenance treatment; 5) special populations (children and adolescents, elderly persons, and women); 6) AD selection according to safety, tolerability, or comorbidity; and 7) non-pharmacological biological therapy (electroconvulsive therapy [ECT], repetitive transcranial magnetic stimulation [rTMS], etc.).
The executive committee decided to include the newer $A D$, such as desvenlafaxine, and vortioxetine. However, some drugs introduced in psychiatric congress but not yet available in Korea, such as levomilnacipran and vilazodone, were not included in this revision (Table 2). In this revision, AAP, such as amisulpride, aripiprazole, blonanserin, clozapine, paliperidone, quetiapine, risperidone, and ziprasidone; and typical antipsychotics were included.

\section{Rating Scale}

Each treatment option was scored on a nine-point scale. Nine indicates extremely appropriate, 7 to 8 indicates usually appropriate, 4 to 6 indicates ambivalence about its appropriateness, 2 to 3 indicates usually inappropriate (a treatment the clinician would rarely use), and 1 indicates extremely inappropriate (a treatment the clinician would never use). The remaining 12 questions, which related to the interval before switching $A D$, the duration of $\mathrm{AD}$ and antipsychotic treatment, and other relevant issues, were open-ended.

When answering, reviewers were asked to consider real practical treatment options rather than ideal practices, and to choose " $q$ " if they had insufficient experience or information to answer a question.

\section{Data Analysis}

Mean of each question or option were calculated. And the presence or absence of consensus on each option/question was determined using a chi-square test to identify differences between groups. No significant difference between groups indicated lack of consensus. We

Table 2. Lists of drugs used in the Korean Medication Algorithm for Depressive Disorder 2017

\begin{tabular}{ll}
\hline Antidepressant & Escitalopram, fluoxetine, fluvoxamine, paroxetine, sertraline \\
& Dsvenlafaxine, duloxetine, milnacipran, venlafaxine \\
& Bupropion \\
& Mirtazapine \\
& Moclobemide \\
& Tianeptine \\
& Agomelatine* \\
& TCA (amitriptyline, clomipramine, imipramine, etc) \\
& Amisulpride, aripiprazole, blonanserin, clozapine, olanzapine, paliperidone, quetiapine, risperidone, \\
Antipsychotics & ziprasidone, typical antipsychotics \\
Mood stabilizer & Carbamazepine, lamotrigine, lithium, valproate \\
Augmentation drugs & Buspirone, gabapentin, ketamine, pindolol, psychostimulant, thyroid hormone, topiramate \\
\hline
\end{tabular}

TCA, tricyclic antidepressant.

*Agomelatine is temporarily withdrawn in Korea, owing to an issue with the management system for insurance issue. 
then calculated the means and 95\% confidence intervals (Cl) of the experts' scores and divided them into three categories according to the lowest 95\% Cl: first-line/preferred treatment, $\geq 6.5$; second-line/reasonable treatment, $<6.5$ and $\geq 3.5$; and third-line/inappropriate treatment, $<3.5$. Treatment of choice (TOC) was defined as an option that was rated at 9 points by $50 \%$ or more of the experts. The SPSS ver. 15.0 software package (SPSS Inc., Chicago, IL, USA) was used for the analyses of preference rankings and multiple responses.

\section{Development of Treatment Guidelines and Algorithms}

After discussing these results and reviewing the current evidences, considering Korean clinical situations, the executive committee drew up the third revised KMAP-DD algorithms (Figs. 1, 2), and will distribute them to the Korean psychiatrists and related experts.

\section{Ethics}

The present study was conducted according to the Declaration of Helsinki. The study protocol was approved by the Institutional Review or Ethics Committee at each study site.

The revision process was funded entirely by KSAD without external financial support.

\section{RESULTS}

\section{Treatment Strategy for Acute Depression with or without Psychotic Features (Table 3)}

Initial strategies for depressive episode

For non-psychotic MDD, mild-to-moderate depressive episodes, AD monotherapy $(95 \% \mathrm{Cl}, 8.5-8.8$ in third revision) was recommended as the TOC in the third revision, as same as in previous revisions. For non-psy-

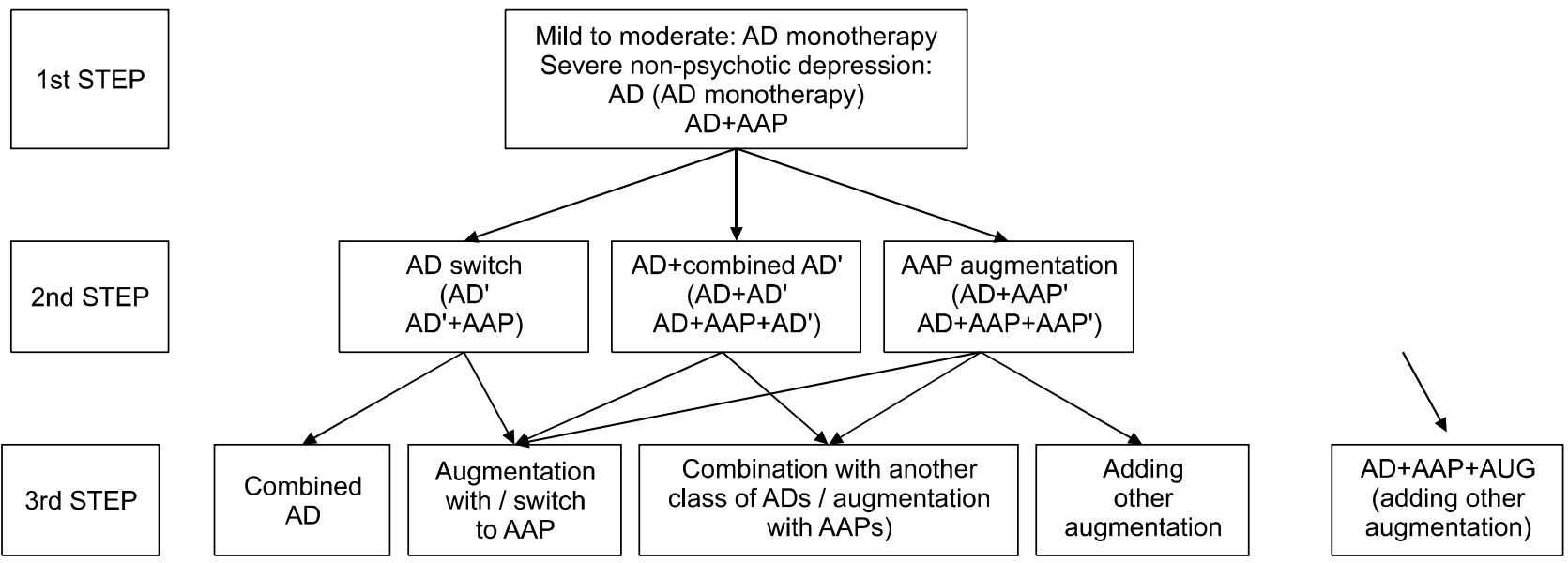

Fig. 1. Korean Medication Algorithm for Depressive Disorder 2017: Non-psychotic depression.

AD, antidepressant; AAP, atypical antipsychotics; AD', another antidepressant; AD", other antidepressant; AAP', another atypical antipsychotics; AAP", other atypical antipsychotics.

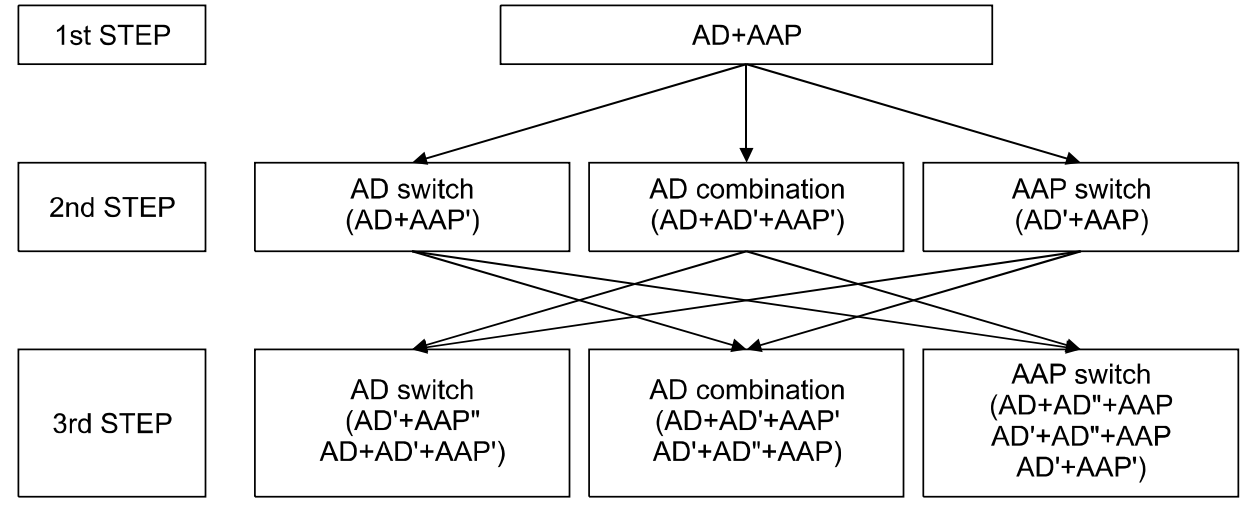

Fig. 2. Korean Medication Algorithm for Depressive Disorder 2017: Psychotic depression.

AD, antidepressant; AAP, atypical antipsychotics; $A D^{\prime}$, another antidepressant; $\mathrm{AD}^{\prime \prime}$, other antidepressant; $\mathrm{AAP}^{\prime}$, another atypical antipsychotics; $\mathrm{AAP}^{\prime \prime}$, other atypical antipsychotics. 
Table 3. Initial and next treatment strategies for depressive disorder between the Korean Medication Algorithm for Depressive Disorder 2017, 2012, and 2006

\begin{tabular}{|c|c|c|c|c|c|c|}
\hline \multirow{2}{*}{$\begin{array}{l}\text { Depressive } \\
\text { episode }\end{array}$} & \multicolumn{2}{|c|}{ Third revision (2017) } & \multicolumn{2}{|c|}{ Second revision (2012) } & \multicolumn{2}{|c|}{ First revision (2006) } \\
\hline & 1st line & 2nd line & 1 st line & 2nd line & 1st line & 2nd line \\
\hline \multicolumn{7}{|l|}{ Initial treatment strategy } \\
\hline $\begin{array}{l}\text { Mild to moderate } \\
\text { episode }\end{array}$ & $\begin{array}{l}\mathrm{AD} \\
\text { monotherapy* }\end{array}$ & $\begin{array}{l}A D+A D \\
A D+A A P \\
A D+M S\end{array}$ & $\begin{array}{l}\mathrm{AD} \\
\text { monotherapy* }\end{array}$ & $\begin{array}{l}A D+A D \\
A D+A A P\end{array}$ & $\begin{array}{l}\mathrm{AD} \\
\text { monotherapy* }\end{array}$ & $\begin{array}{l}A D+A D \\
A D+A \cup G\end{array}$ \\
\hline Severe episode & $\begin{array}{l}\mathrm{AD} \\
\text { monotherapy } \\
\mathrm{AD}+\mathrm{AAP}\end{array}$ & $\begin{array}{l}\text { AAP } \\
\text { monotherapy } \\
\text { AD+AD } \\
\text { AD+MS } \\
\text { ECT }\end{array}$ & $\begin{array}{l}\text { AD } \\
\text { monotherapy }\end{array}$ & $\begin{array}{l}\mathrm{AD}+\mathrm{AAP} \\
\mathrm{AAP} \\
\quad \text { monotherapy } \\
\mathrm{AD}+\mathrm{AD} \\
\mathrm{ECT}\end{array}$ & $\begin{array}{l}\text { AD } \\
\text { monotherapy }\end{array}$ & $\begin{array}{l}A D+A D \\
A D+A A P \\
A D+A \cup G\end{array}$ \\
\hline $\begin{array}{l}\text { Psychotic } \\
\text { depression }\end{array}$ & $\mathrm{AD}+\mathrm{AAP}^{*}$ & & $\mathrm{AD}+\mathrm{AAP}^{*}$ & $\begin{array}{l}\mathrm{AD}+\mathrm{TAP} \\
\mathrm{AAP} \\
\text { monotherapy } \\
\mathrm{ECT} \\
\mathrm{AD}+\mathrm{AD} \\
\mathrm{AD} \text { monotherapy }\end{array}$ & $\mathrm{AD}+\mathrm{AAP}^{*}$ & $\begin{array}{l}\text { AD + TAP } \\
\mathrm{ECT} \\
\mathrm{AD}+\mathrm{AD} \\
\mathrm{AD}+\mathrm{A} \cup \mathrm{G} \\
\mathrm{AD} \text { monotherapy } \\
\text { AAP monotherapy }\end{array}$ \\
\hline \multicolumn{7}{|l|}{ 2nd treatment strategy } \\
\hline $\begin{array}{l}\text { Mild to moderate } \\
\text { episode (No } \\
\text { response) }\end{array}$ & $\begin{array}{l}\text { Switching AD } \\
\text { Adding AD } \\
\text { Adding AAP }\end{array}$ & AUG & $\begin{array}{l}\text { Switching } A D \\
\text { Adding other } A D\end{array}$ & $\begin{array}{l}\text { Adding AAP } \\
\text { AUG }\end{array}$ & $\begin{array}{l}\text { Switching } A D \\
\text { Adding other } A D\end{array}$ & $\begin{array}{l}\text { AUG } \\
\text { Adding AAP }\end{array}$ \\
\hline $\begin{array}{l}\text { Severe episode } \\
\text { (Partial response) }\end{array}$ & $\begin{array}{l}\text { Adding AD } \\
\text { Adding AAP }\end{array}$ & $\begin{array}{l}\text { Switching AD } \\
\text { AUG }\end{array}$ & $\begin{array}{l}\text { Adding other AD } \\
\text { Adding AAP }\end{array}$ & $\begin{array}{l}\text { AUG } \\
\text { Switching AD }\end{array}$ & $\begin{array}{l}\text { Adding other } \mathrm{AD} \\
\mathrm{A} \cup \mathrm{G}\end{array}$ & $\begin{array}{l}\text { Switching AD } \\
\text { Adding AAP }\end{array}$ \\
\hline $\begin{array}{l}\text { Psychotic depression } \\
\text { (Inadequate } \\
\text { response) }\end{array}$ & $\begin{array}{l}\text { Switching AAP } \\
\text { Adding AD } \\
\text { Switching AD }\end{array}$ & $\begin{array}{l}\text { Adding AAP } \\
\text { AUG } \\
\text { Adding TAP }\end{array}$ & $\begin{array}{l}\text { Adding other AD } \\
\text { Switching AAP } \\
\text { Switching AD }\end{array}$ & $\begin{array}{l}\text { Adding other } \\
\text { AAP } \\
\text { AUG } \\
\text { Adding TAP }\end{array}$ & $\begin{array}{l}\text { Adding AAP } \\
\text { Switching AD } \\
\text { Adding other AD }\end{array}$ & AUG \\
\hline
\end{tabular}

$A D$, antidepressant; AAP, atypical antipsychotics; MS, mood stabilizer; AUG, augmenting drugs (buspirone, gabapentinm, ketamine, pindolol, psychostimulant, thyroid hormone, topiramate); ECT, electroconvulsive therapy; TAP, typical antipsychotics.

${ }^{*}$ Treatment of choice, defined as an option that was rated at 9 points by $50 \%$ or more of the experts.

Table 4. Comparison of preference of antipsychotics in the Korean Medication Algorithm for Depressive Disorder

\begin{tabular}{|c|c|c|c|c|c|}
\hline \multirow{2}{*}{$\begin{array}{l}\text { Preference of atypical } \\
\text { antipsychotics }\end{array}$} & \multicolumn{2}{|c|}{ Third revision (2017) } & \multicolumn{2}{|c|}{ Second revision (2012) } & \multirow{2}{*}{$\begin{array}{l}\text { First revision (2006) } \\
\text { (when using AP) }\end{array}$} \\
\hline & Non-psychotic & Psychotic & Non-psychotic & Psychotic & \\
\hline Amisulpride & $5.0(4.6-5.5)$ & $6.0(5.6-6.3)$ & $5.5(5.0-5.9)$ & $6.6(6.1-7.0)$ & $5.8(5.3-6.2)$ \\
\hline Aripiprazole & $8.3(8.2-8.5)^{*}{ }^{\dagger}$ & $8.3(8.1-8.5)^{*}$ & $7.9(7.6-8.2)^{*}$ & $7.9(7.6-8.2)^{*}$ & $6.3(5.8-6.7)$ \\
\hline Blonanserin & $4.6(4.2-5.0)$ & $6.1(5.7-6.5)$ & $4.4(3.7-5.1)$ & $5.8(5.1-6.4)$ & - \\
\hline Clozapine & $2.7(2.3-3.1)$ & $3.9(3.4-4.3)$ & $2.9(2.4-3.4)$ & $4.1(3.6-4.6)$ & $3.5(3.0-4.0)$ \\
\hline Olanzapine & $6.0(5.6-6.4)$ & $7.3(7.0-7.7)^{*}$ & $6.6(6.2-7.0)$ & $7.6(7.3-7.9)^{*}$ & $7.1(6.7-7.5)^{*}$ \\
\hline Paliperidone & $4.5(4.1-5.0)$ & $6.9(5.6-6.5)$ & - & - & - \\
\hline Quetiapine & $7.8(7.6-8.0)^{*}$ & $7.9(7.7-8.1)^{*}$ & $7.7(7.4-8.0)^{*}$ & $8.1(7.8-8.3)^{*}$ & $7.3(6.9-7.7)^{*}$ \\
\hline Risperidone & $5.3(4.8-5.7)$ & $6.7(6.3-7.1)$ & $6.0(5.5-6.4)$ & $7.3(6.9-7.6)^{*}$ & $7.3(6.9-7.7)^{*}$ \\
\hline Ziprasidone & $5.1(4.6-5.6)$ & $5.9(5.6-6.3)$ & $5.7(5.2-6.3)$ & $6.5(6.1-6.9)$ & $6.5(6.0-6.9)$ \\
\hline Typical antipsychotics & $2.9(2.5-3.3)$ & $4.0(3.4-4.3)$ & $3.2(2.8-3.6)$ & $4.5(4.0-5.0)$ & $4.8(4.3-5.3)$ \\
\hline
\end{tabular}

Values are presented as mean ( $95 \%$ confidence interval).

$\mathrm{AP}$, antipsychotics.

*First-line drug maximum score of preference is 9 points.

${ }^{\dagger}$ Treatment of choice, defined as an option that was rated at 9 points by $50 \%$ or more of the experts.

chotic severe episode, $A D$ monotherapy and $A D+A A P$ were the preferred (first-line) strategy, which indicates that preference for AAP was increased over that of the pre- vious KMAP series (Table 4). For psychotic severe episode, $\mathrm{AD}+\mathrm{AAP}$ was the TOC in all three KMAP-DD revisions. 
Second strategies when initial strategies have no or partial response

When the patient is unresponsive to initial strategies, switching and adding AD or AAP were preferred, while with a partial response, switching was preferred to add other drugs.

\section{AD Choices}

Preferred AD for initial treatment

For mild-to-moderate depressive episodes, escitalopram $(95 \% \mathrm{Cl}, 8.4-8.7)$ and sertraline $(95 \% \mathrm{Cl}, 7.8-8.2)$ were the TOCs and fluoxetine, paroxetine, serotonin-norepinephrine reuptake inhibitors (SNRIs, duloxetine, milnacipran, venlafaxine, desvenlafaxine), and mirtazapine were recommended as first-line AD treatments. For nonpsychotic severe episodes, escitalopram, venlafaxine, and mirtazapine were the TOC, and fluoxetine, paroxetine, sertraline, duloxetine, and desvenlafaxine were the first-line drugs. For psychotic depression, escitalopram was the TOC, and other selective serotonin reuptake inhibitors (SSRIs) except fluvoxamine, SNRIs, and mirtazapine were the first-line drugs.

AD choice in light of adverse effects, safety, and comorbid physical illness

We asked the experts to choose three ADs when considering adverse effect, drug safety, and comorbid physical illness, respectively. Considering adverse effect, bupropion, mirtazapine, and tianeptine were preferred in terms of sexual dysfunction. Bupropion, fluoxetine, and escitalopram were preferred for sedation and somnolence. For weight gain, fluoxetine, bupropion, and tianeptine were preferred. For insomnia, mirtazapine, paroxetine, and tricyclic antidepressants (TCAs) were preferred. For gastrointestinal (Gl) trouble, mirtazapine, tianeptine and bupropion were recommended. For anticholinergic side effect, escitalopram, sertraline, and bupropion were selected.

In matters of safety, for hypo- or hypertension, escitalopram, sertraline, and tianeptine; for serotonin syndrome, bupropion, tianeptine, and agomelatine; for seizure, escitalopram, sertraline, and tianeptine; for arrhythmia, escitalopram, sertraline, and tianeptine; for suicidality, mirtazapine, bupropion, and tianeptine were recommended.

In matters of comorbid physical illness, escitalopram and sertraline were recommended as first-line AD considering diabetes mellitus, thyroid disease, liver disease, and renal disease.

Organizing these findings by drug, bupropion was recommended by the Korean expert group based on considerations of sexual dysfunction, sedation, and weight gain. Furthermore, mirtazapine was a preferred AD based on considerations of insomnia, Gl problems, and suicidality. Escitalopram was preferred based on considerations of anticholinergic side effects, hypo- or hypertension, arrhythmia, seizures, diabetes mellitus, and diseases of thyroid, liver, or kidney.

\section{Treatment Duration with Initial AD before Next Strategy (Switching to or Adding Other AD, etc.) and Maintenance Treatment}

Treatment duration with initial AD until switching to another AD

The experts were asked "How long do you keep using the initial drug until the next strategic change, such as switching or adding, due to lack of efficacy?"

With AD monotherapy for non-psychotic mild-to-moderate depressive episode, their answer was a minimum, $2.92( \pm 1.39)$ to maximum, $6.41( \pm 3.64)$ weeks. With AD monotherapy for severe episode, the answer was 2.82 $( \pm 2.35)$ to $6.05( \pm 5.34)$ weeks. When there is no response to the initial AD for psychotic depression, they wait for $2.34( \pm 1.95)$ to $4.71( \pm 3.77)$ weeks, while with partial response they wait for $3.37( \pm 1.86)$ to $6.49( \pm 3.69)$ weeks. When there is no response to AAP for psychotic depression, their answer was $2.26( \pm 1.91)$ to $4.61( \pm 3.77)$ weeks, while with partial response the answer was $3.28( \pm 1.76)$ to $6.26( \pm 3.09)$ weeks.

Duration of maintenance treatment of psychotic depression after remission (Table 5)

The duration of AD+AAP treatment for psychotic depression after remission depends on the number of depressive episodes experienced by the patient. The majority of experts (86\% for first episode; $54 \%$ for second episode) recommended that the ongoing AD treatment be stopped 19.8 to 46.8 weeks after the first episode and 34.8 to 78.4 weeks after a second episode. Experts recommended that the initial AAP therapy be maintained for 13.1 to 31.3 weeks for a first episode and 21.6 to 49.8 weeks for a second episode. 
However, following three or more episodes, $66 \%$ of the respondents recommended, "maintaining the ongoing AD as long as possible," and 62.0\% recommended, "maintaining the ongoing AAP as long as possible."

\section{Maintenance dose of ongoing AD and AAP after} remission

The experts were asked, "How long do you maintain the dosage of ongoing drugs after remission, if there are no safety issues?" Most experts recommended maintaining
$75 \%$ of the AD dose and $50 \%$ of the AAP dose used in the acute stage.

\section{Treatment Strategies for Persistent Depressive Disorder (Dysthymia) and Strategies according Subtype or with Specifiers Mixed or Anxious distress}

Treatment strategies for persistent depressive disorder AD monotherapy with escitalopram was the TOC for persistent depressive disorder.

Table 5. Duration of maintenance treatment

\begin{tabular}{|c|c|c|c|c|c|}
\hline \multirow{2}{*}{$\begin{array}{l}\text { Ongoing } \\
\text { drug }\end{array}$} & \multirow{2}{*}{$\begin{array}{c}\text { Number of } \\
\text { depressive episode }\end{array}$} & \multirow{2}{*}{$\begin{array}{l}\text { Taper and } \\
\text { discontinue }\end{array}$} & \multicolumn{2}{|c|}{ After using some duration, taper and discontinue } & \multirow{2}{*}{$\begin{array}{c}\text { Maintain } \\
\text { continuously }\end{array}$} \\
\hline & & & Number (\%) & Duration (wk) & \\
\hline \multirow[t]{3}{*}{$\mathrm{AD}$} & 1 & 0 & $68(86.0)$ & $19.8-46.8$ & $11(14.0)$ \\
\hline & 2 & 0 & $54(68.4)$ & $34.8-78.4$ & 25 (31.6) \\
\hline & 3 or more & 0 & $13(16.5)$ & $41.8-88.9$ & $66(83.5)$ \\
\hline \multirow[t]{3}{*}{ AAP } & 1 & $12(15.2)$ & $61(77.2)$ & $13.1-31.3$ & $6(7.6)$ \\
\hline & 2 & $3(3.8)$ & $61(77.2)$ & $21.6-49.8$ & 15 (19.0) \\
\hline & 3 or more & $1(1.3)$ & $29(36.7)$ & $28.8-59.6$ & $49(62.0)$ \\
\hline
\end{tabular}

Values are presented as number only, number (\%), or week only.

Shown are the results of question 27-1 ("A patient with major depressive episode with psychotic features was treated with antidepressant and antipsychotics and achieved remission. How long will you continue prescribing antidepressant or atypical antipsychotics given the history of depressive episodes?").

AD, antidepressant; AAP, atypical antipsychotics.

Table 6. Initial treatment strategies and drugs of choice for anxious distress or mixed features

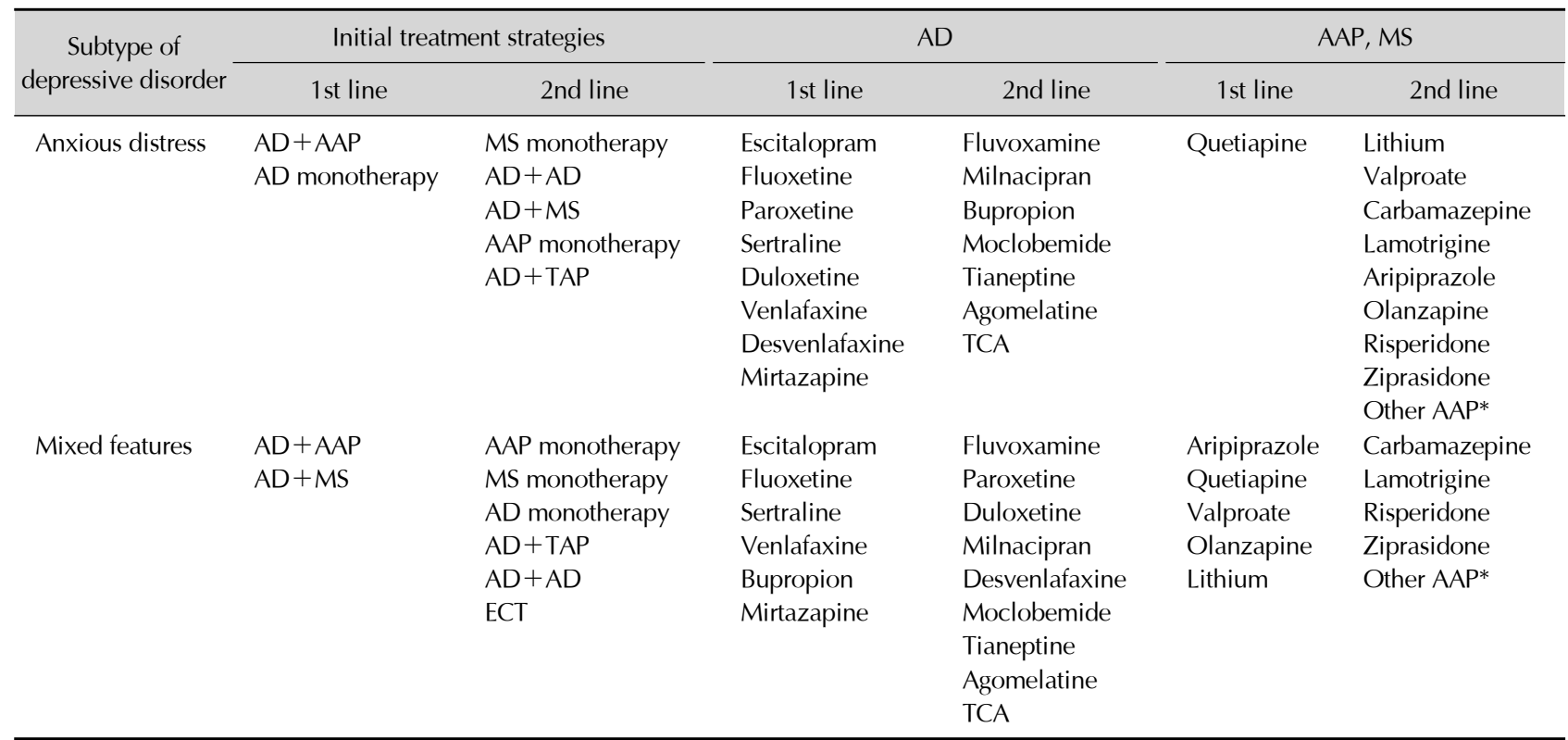

AD, antidepressant; AAP, atypical antipsychotics; MS, mood stabilizer; TAP, typical antipsychotics; ECT, electroconvulsive therapy; TCA, tricyclic antidepressant.

*Amisupride, blonanserin, clozapine, paliperidone. 
AD choice according subtype of depressive episode

For the patients with melancholic features, escitalopram and venlafaxine were the TOC and fluoxetine, paroxetine, sertraline, duloxetine, milnacipran, desvenlafaxine, and mirtazapine were the first-line ADs. With regard to atypical and seasonal depression, escitalopram, fluoxetine, sertraline, SNRIs, bupropion, and mirtazapine were commonly recommended as first-line treatments. Paroxetine was the first-line treatment for seasonal pattern, but not for atypical features.

Treatment strategies and AD choice according specifiers, mixed features and anxious distress in depressive episode (Table 6)

For mixed features, $\mathrm{AD}+\mathrm{AAP}$ and $\mathrm{AD}+$ mood stabilizer (MS) were the first-line strategies and AAP, MS, or AD monotherapy were recommended not as first-line, but as second-line strategies. As preferred ADs, escitalopram, fluoxetine, sertraline, venlafaxine, bupropion, and mirtazapine were recommended, and as MSs, lithium, valproate, aripiprazole, olanzapine, and quetiapine were recommended. These strategies indicate that when treating MDD with mixed features, the experts would be cautious or concerned about manic switching or bipolarity.

With regard to anxious distress, AD monotherapy or $A D+A A P$ were the initial treatment strategies. MS monotherapy, $A D+A D, A D+M S, A A P$ monotherapy, $A D+$ TAP and ECT were recommended as the second strategies. As an initial $A D$, escitalopram, fluoxetine, paroxetine, sertraline, duloxetine, venlafaxine, desvenlafaxine, and mirtazapine were preferred. And quetiapine was the first AAP for anixious distress.

\section{Treatment Strategies for Special Populations (Table 7)}

Depressive disorder in child or adolescent

In contrast to MDD in adults, the results on children and adolescents with MDD contained more "no consensus" values. There is no first-line treatment for disruptive mood dysregulation disorder (DMDD). AAP, MS, or $\mathrm{AD}$ monotherapy were recommended as second-line treatment. Only escitalopram and aripiprazole were first-line ADs and AAPs, respectively.

$A D$ monotherapy for non-psychotic severe episodes was the recommended first-line treatment for children and adolescents with mild-to-moderate and severe de- pressive episodes without psychotic features. The combination of $\mathrm{AD}+\mathrm{AAP}$ was recommended as the first-line treatment for severe episodes with psychotic features. Escitalopram and fluoxetine were the first-line ADs. AD+ AAP for psychotic depression was the recommended first-line strategy, escitalopram and fluoxetine the recommended ADs, and aripiprazole and risperidone the recommended AAPs.

Elderly patients with MDD

AD monotherapy was the TOC for geriatric patients with mild-to-moderate depressive episodes. AD monotherapy and $\mathrm{AD}+\mathrm{AAP}$ were the first-line strategies for severe episodes without psychotic features, whereas combination therapy with $\mathrm{AD}+\mathrm{AAP}$ was the TOC for severe episodes with psychotic features. Moreover, escitalopram was a TOC for all three types of episode.

Women with depressive disorder

AD monotherapy was the first-line treatment option for premenstrual dysphoric disorder (PMDD). Escitalopram was a TOC for PMDD.

For MDD in pregnancy, AD monotherapy was recommended as a first-line treatment for mild-to-moderate and non-psychotic, severe depression. However, AD+AAP and ECT were recommended for psychotic severe depression. For postpartum depression, $A D$ monotherapy was the TOC for mild-to-moderate episodes, and both $A D$ monotherapy and combination therapy with $\mathrm{AD}$ and $\mathrm{AAP}$ were recommended as the first-line treatment for severe episodes without psychotic features. For severe episodes with psychotic features, $A D+A A P$ were the recommended TOC.

\section{Non-pharmacological Biological Treatment}

\section{ECT (Fig. 3)}

Ninety-two percent of experts considered ECT a MDD treatment modality and $46.8 \%$ of experts were applying it for MDD in clinical practice. On average, one expert conducts ECT with 5.6 persons per year, with 2.9 sessions per patient per week, totaling 9.6 sessions per patient during one treatment plan. The first-line indications for ECT were urgent suicidal risks in patients with non- or psychotic severe episode, non-responder on pharmacotherapy with moderate episode, or severe episode in pregnant patient. 


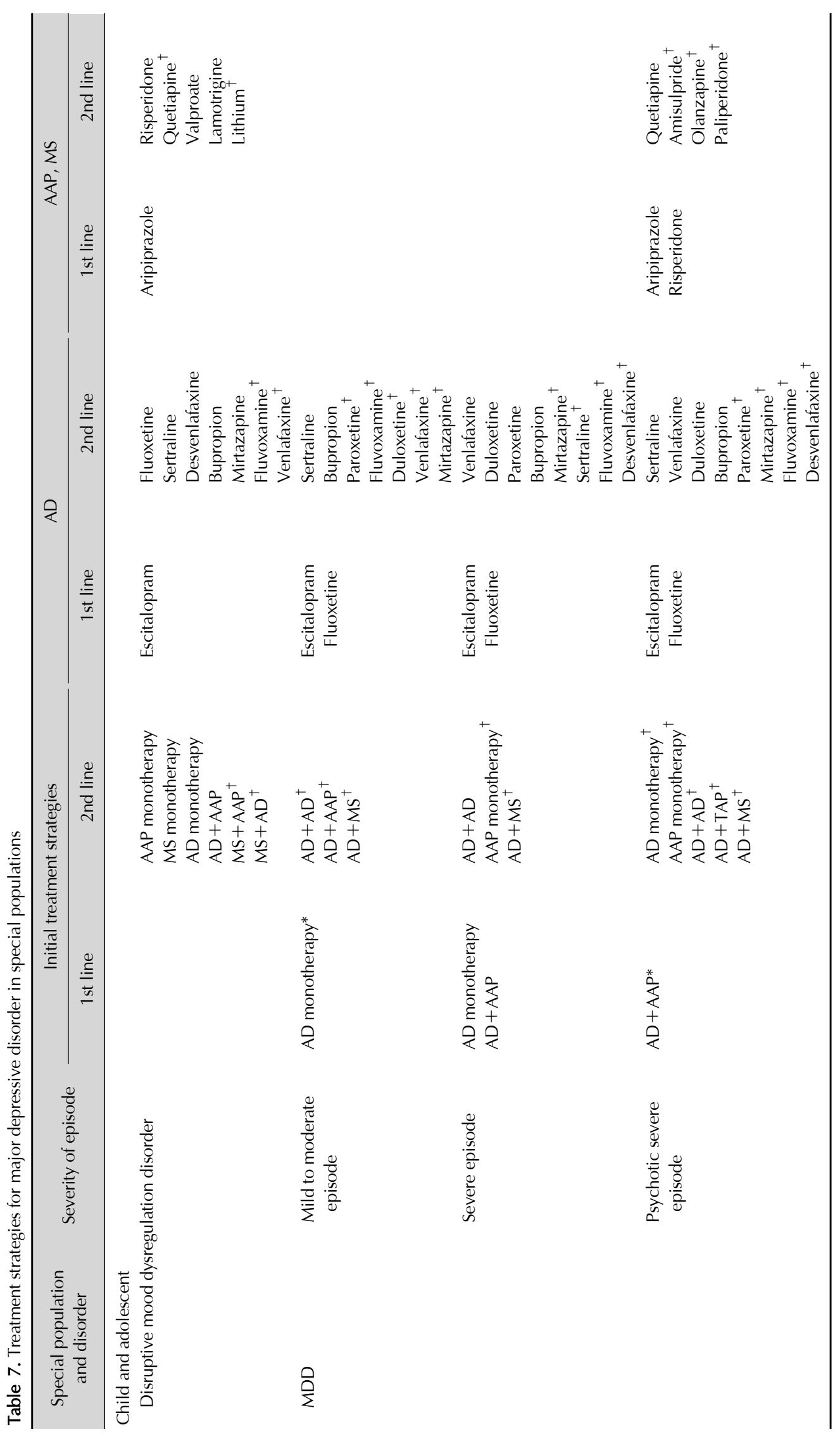




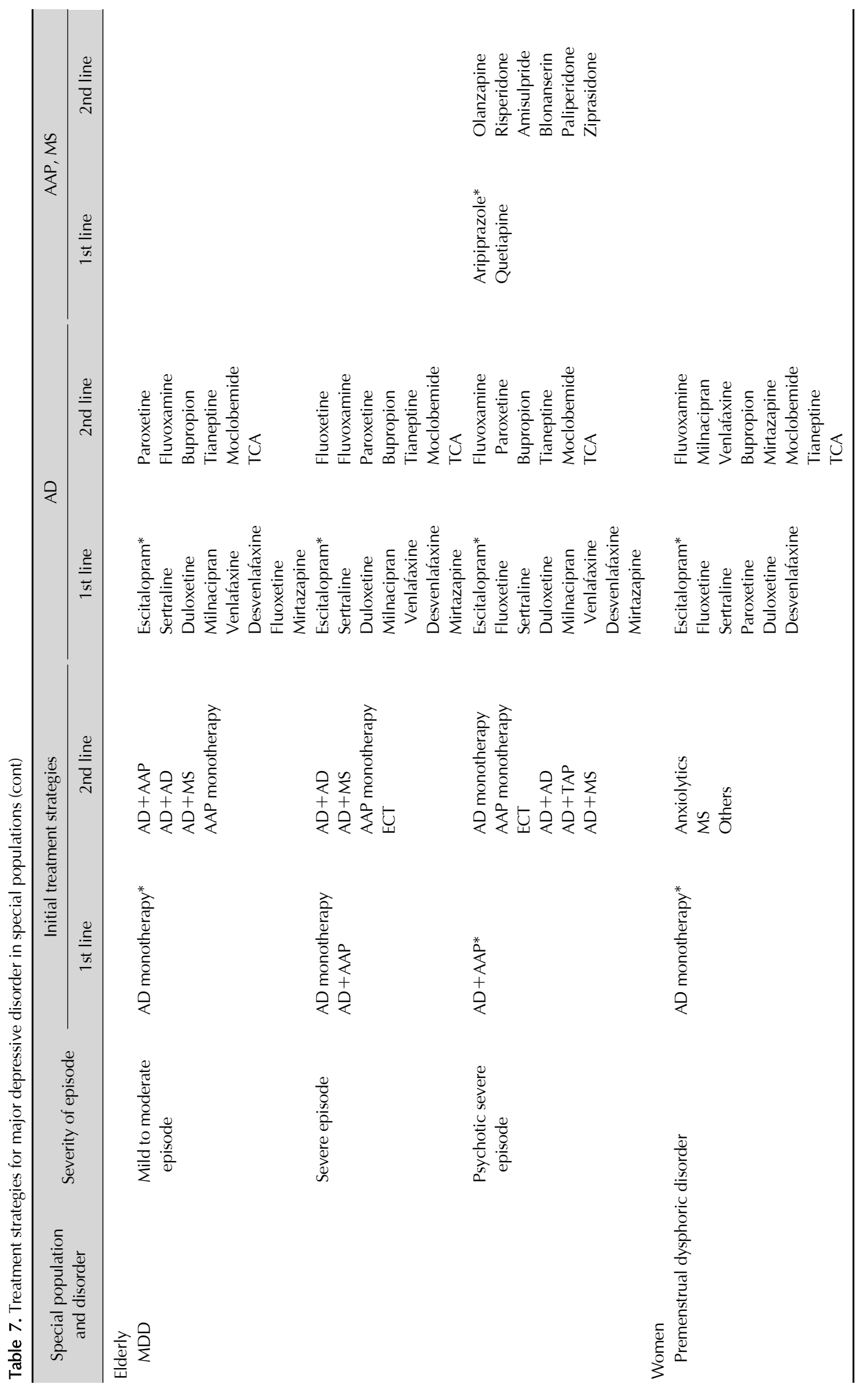




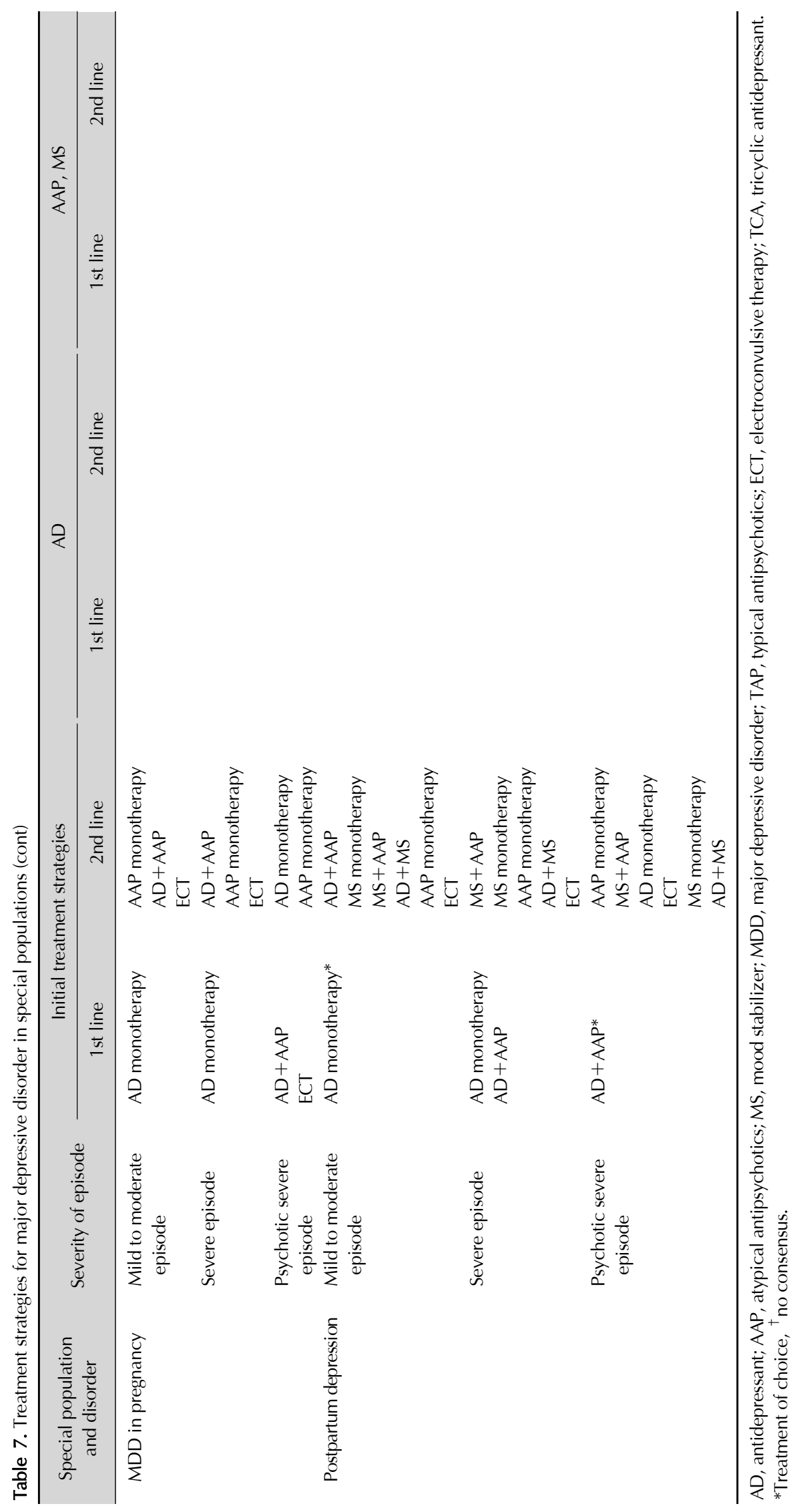




\begin{tabular}{|c|c|c|c|c|c|c|c|c|}
\hline & & 3rd line & $\begin{array}{l}95 \% \mathrm{Cl} \\
\text { 2nd line }\end{array}$ & 1st line & $\begin{array}{l}\text { Mean } \\
(\mathrm{SD})\end{array}$ & $\begin{array}{c}1 \mathrm{st} \\
\text { line }(\%)\end{array}$ & $\begin{array}{l}\text { 2nd } \\
\text { line }(\%)\end{array}$ & $\begin{array}{c}\text { 3rd } \\
\text { line }(\%)\end{array}$ \\
\hline \multirow{5}{*}{$\begin{array}{l}\text { Severe } \\
\text { episode } \\
\text { without } \\
\text { psychotic } \\
\text { features }\end{array}$} & Urgent suicidal risks & & & & $7.7(1.4)$ & 86.1 & 11.1 & 2.8 \\
\hline & Comorbid with physical illness & & & & $6.3(2.2)$ & 59.7 & 25.0 & 15.3 \\
\hline & $\begin{array}{l}\text { Non-responders on ADs } \\
\text { combination therapy }\end{array}$ & & & & $5.7(2.0)$ & 41.9 & 45.9 & 12.2 \\
\hline & Non-responders on an ADs & & & & $3.7(1.8)$ & 8.2 & 46.6 & 45.2 \\
\hline & $\begin{array}{l}\text { First line treatment for ADs } \\
\text { naive patients }\end{array}$ & & & & $2.4(1.4)$ & & 20.5 & 79.5 \\
\hline \multirow{4}{*}{$\begin{array}{l}\text { Severe } \\
\text { episode } \\
\text { with } \\
\text { psychotic } \\
\text { features }\end{array}$} & Urgent suicidal risks* & & & & $8.0(1.3)^{*}$ & $89.2^{*}$ & 9.5 & 1.4 \\
\hline & $\begin{array}{l}\text { Non-responders on APs and } \\
\text { ADs combination therapy }\end{array}$ & & & & $6.6(1.8)$ & 60.8 & 35.1 & 4.1 \\
\hline & Comorbid with physical illness & & & & $6.5(2.1)$ & 64.9 & 24.3 & 10.8 \\
\hline & $\begin{array}{l}\text { First line treatment for ADs } \\
\text { naive patients }\end{array}$ & & & & $3.7(1.9)$ & 9.7 & 34.7 & 55.6 \\
\hline \multicolumn{2}{|c|}{$\begin{array}{l}\text { Nonresponders on } \\
\text { pharmacotherapy, moderate episode }\end{array}$} & & & & $7.5(1.6)$ & 69.9 & 28.8 & 1.4 \\
\hline \multicolumn{2}{|c|}{ Severe episode in pregnant patient } & & & & $7.1(1.5)$ & 76.7 & 21.9 & 1.4 \\
\hline
\end{tabular}

First-line treatment

Second-line treatment

Third-line treatment

Fig. 3. Indications of electro-convulsive therapy.

95\% Cl, 95\% confidential interval; SD, standard deviation; ADs, antidepressants; APs, antipsychotics.

*Treatment of choice.

Indications for rTMS (Fig. 4)

Eighty-six percent of experts considered rTMS an MDD treatment option, but only $31.6 \%$ apply it in clinical practice for MDD. On average, one expert conducts rTMS with 12.7 persons per year, with 4.1 sessions per patient per week, totaling 12.6 sessions per patient during one treatment plan. In Korea, experts recommended rTMS as a second-line treatment option for MDD without urgent risks.

Choice of complementary or novel agents for treatment-resistant depressive disorder

Light therapy, nutritional therapy (omega-3, megavitamin), vagus nerve stimulation, S-adenosylmethionine, deep brain stimulation, and sleep deprivation were considered as second-line treatment options for MDD.

\section{DISCUSSION}

\section{Are Expert Consensus and Evidence-based Guidelines Contradictory?}

There are two types of guidelines, experts' consensus and evidence-based. Most evidences are derived from randomized controlled trials (RCTs) with strict inclusion and exclusion criteria that do not reflect the complexity of various real clinical situations, and from meta-analyses of RCTs. Thus, there can be a gap between real-world practice and evidence from RCTs. Moreover, common problems of meta-analyses include small sample size, inadequate power, study heterogeneity, lack of extractable data, lack of interchangeable measurement instruments and definitions of outcomes, and other differences in the design of the studies whose data are utilized. On the other hand, clinical-consensus guidelines have a common problem that overall reliability and validity is question- 


\begin{tabular}{|c|c|c|c|c|c|c|c|c|}
\hline & & 3rd line & $\begin{array}{l}95 \% \mathrm{Cl} \\
\text { 2nd line }\end{array}$ & 1st line & $\begin{array}{l}\text { Mean } \\
\text { (SD) }\end{array}$ & $\begin{array}{c}1 \mathrm{st} \\
\text { line }(\%)\end{array}$ & $\begin{array}{l}\text { 2nd } \\
\text { line }(\%)\end{array}$ & $\begin{array}{l}\text { 3rd } \\
\text { line }(\%)\end{array}$ \\
\hline \multirow{5}{*}{$\begin{array}{l}\text { Severe } \\
\text { episode } \\
\text { without } \\
\text { psychotic } \\
\text { features }\end{array}$} & $\begin{array}{l}\text { Non-responders on ADs } \\
\text { combination therapy }\end{array}$ & & & & $6.4(1.9)$ & 51.6 & 40.6 & 7.8 \\
\hline & Comorbid with physical illness & & & & $6.2(1.9)$ & 57.8 & 31.3 & 10.9 \\
\hline & Urgent suicidal risks & & & & $5.4(1.8)$ & 25.0 & 65.2 & 12.5 \\
\hline & Non-responders on an ADs & & & & $5.4(2.1)$ & 37.5 & 43.8 & 18.8 \\
\hline & $\begin{array}{l}\text { First line treatment for ADs } \\
\text { naive patients }\end{array}$ & & & & $4.4(2.3)$ & 14.5 & 45.2 & 40.3 \\
\hline \multirow{4}{*}{$\begin{array}{l}\text { Severe } \\
\text { episode } \\
\text { with } \\
\text { psychotic } \\
\text { features }\end{array}$} & Comorbid with physical illness & & & & $6.0(1.9)$ & 51.6 & 35.9 & 12.5 \\
\hline & $\begin{array}{l}\text { Non-responders on AP and } \\
\text { ADs combination therapy }\end{array}$ & & & & $5.7(1.9)$ & 38.1 & 49.2 & 12.7 \\
\hline & Urgent suicidal risks & & & & $5.6(2.0)$ & 34.4 & 50.0 & 15.6 \\
\hline & $\begin{array}{l}\text { First line treatment for ADs } \\
\text { naive patients }\end{array}$ & & & & $4.1(2.0)$ & 10.9 & 45.3 & 43.8 \\
\hline \multicolumn{2}{|c|}{$\begin{array}{l}\text { Non-responders on } \\
\text { pharmacotherapy, moderate episode }\end{array}$} & & & & $6.5(1.6)$ & 51.6 & 45.3 & 3.1 \\
\hline \multicolumn{2}{|c|}{ Severe episode in pregnant patient } & & & & $6.5(1.9)$ & 59.4 & 32.8 & 7.8 \\
\hline
\end{tabular}

Second-line treatment

Fig. 4. Indications of repetitive transcranial magnetic stimulation. 95\% Cl, 95\% confidential interval; SD, standard deviation; ADs, antidepressants; APs, antipsychotics.

able. $^{6)}$

Our process for the present revision had two phases. First, we focused on the consensus emerging from various clinical situations, which RCTs cannot assess. We thereafter proceeded to an open discussion that addressed and evaluated the evidence. The recent guidelines of the Canadian Network for Mood and Anxiety Treatment has introduced the concept that the basis of guidelines should be balanced between systematic reviews and consensus expert opinion obtained from experienced clinicians, rather than depending exclusively on formalized evidence summaries. ${ }^{7)}$ We agree with Möller, ${ }^{8)}$ the first speaker on the International College of Neuropsychopharmacology (CINP) treatment guidelines for bipolar disorder at the 2016 CINP world seminar in Korea, who said that evidence-based and clinical-experience-based medicine are not contradictory, but complementary. For example, treatment recommendations for MDD with mixed features or with anxious distress or DMDD can be based on expert experience in the current absence of RCT-based evidence, with the proviso that the recommendations be validated by such evidence in the near future.

\section{Treatment Strategy for Non- or Psychotic Depression}

The preferred initial treatment strategy for non-psychotic MDD was AD monotherapy regardless of the severity of the depressive episode, as recommended in KMAP-DD 2012 and 2006. Compared with previous revisions, the notable finding in this revision is that preference for AAP has increased (Table 4); In KMAP-DD 2012 and 2006, the combination of AD+AAP was the second-line treatment, but in this revision, $A D+A A P$ were recommended as a first-line strategy for non-psychotic severe episode. It was also recommended as a second strategy when the initial strategies give no- or partial responses. In the third revision, adding AAP was the preferred next strategy, while adding AAP was second-line among next strategies (Table 3). Although the recommendation grade for AAP as an initial treatment in nonpsychotic depression is weak, ${ }^{9)}$ adjunctive AAP treatment 
in treatment-resistant depression (TRD) or failure of initial $\mathrm{AD}$ treatment has consistent supporting evidence, ${ }^{10-13)}$ and is recommended in various guidelines, such as the Texas Medication Algorithm Project, Major Depressive Disorder Algorithms ${ }^{14)}$ and the World Federation of Societies of Biological Psychiatry Guidelines for Biological Treatment of Unipolar Depressive Disorders (WFSBP 2013). ${ }^{15)}$

Increased preference for AAP reflects the efficacy of AAP in the treatment of non-psychotic MDD as well as TRD. Nelson and Papakostas ${ }^{16)}$ reported that in their meta-analysis of 16 trials $(n=3,480)$, adjunctive AAP significantly achieved more responses than $\mathrm{AD}$ monotherapy (odds ratio [OR], 1.69; 95\% Cl, 1.46-1.95; $p<$ $0.00001)$, as well as higher remission rates (OR, 2.00; 95\% Cl, 1.69-2.37; $p<0.00001)$. Moreover, Canadian Network for Mood and Anxiety Treatments (CANMAT) 2016 recommended aripiprazole, quetiapine, and risperidone as first-line adjunctive drugs for nonresponse or partial response to an initial AD. ${ }^{17)}$

AAP treatment is associated with an increased risk of discontinuation due to adverse events ${ }^{16)}$ and is less well tolerated than are SSRIs ${ }^{18)}$; thus, AAP augmentation, rather than AAP monotherapy, may be more appropriate for patients with nonpsychotic MDD.

In the comparison between clinical guidelines of MDD by Wang et al., ${ }^{19)}$ such as APA 2010, ${ }^{20)}$ WFSBP 2013, ${ }^{15)}$ CANMAT 2016, ${ }^{17)}$ and National Institute for Clinical Excellence (NICE) 2009, ${ }^{21)}$ these guidelines recommended $A D$ monotherapy as a first-line treatment for MDD without psychotic features while AD+AAP as well as $A D$ monotherapy were recommended for the treatment of severe depressive episode without psychotic features in KMAP-DD 2017, which suggested the increased preference of AAP in Korea.

For psychotic depression, $\mathrm{AD}+\mathrm{AAP}$ is the TOC in this revision, as in previous revisions. WFSBP 2013 presented $\mathrm{AD}+\mathrm{AAP}$ as recommendation grade 3 (defined as limited positive evidence from controlled trials). ${ }^{15}$ It is not clear which is more effective, adding or switching within the same class of AD or using a different class. Connolly and Thase ${ }^{22)}$ concluded that the strength of the evidence supporting augmentation and that supporting switching to a new agent after failure of a first-line SSRI were similar, with remission rates between $25 \%$ and $50 \%$; thus, the data did not provide unequivocal support for either switch- ing within or switching between AD classes. However, CANMAT $2009^{18)}$ summarized evidence that switching to another $\mathrm{AD}$ in non-responders results in good response and remission rates, and CANMAT $2016^{17)}$ recommended switching to another $A D$ in cases of no response to the initial treatment, or adding another $\mathrm{AD}$ in cases of partial response to initial treatment, which is consistent with KMAP-DD third revision.

\section{AD Choice}

Preferred AD and as initial treatment

The results that escitalopram and sertraline were the TOC for non-psychotic mild-to-moderate and severe episode, and escitalopram was the TOC for psychotic depression are in contrast to those of KMAP-DD 2012, in which there was no TOC among the ADs. These results are similar to those of Cipriani et al., ${ }^{23)}$ who published a network meta-analysis showing that among 12 second-generation ADs, escitalopram, mirtazapine, sertraline, and venlafaxine had superior response relative to other ADs. The results that SSRIs except fluvoxamine, SNRIs except milnacipran, and mirtazapine were recommended for first-line AD treatment of psychotic depression show a trend of $A D$ choice similar to that of KMAP-DD 2012. CANMAT 2016 recommended vortioxetine as well as SSRIs, SNRIs, agomelatine, bupropion, and mirtazapine as first-line. ${ }^{17)}$ Interestingly, quetiapine was recommended as a second-line AD with TCAs, trazodone, moclobemide, selegiline, levomilnacipran, and vilazodone. Although agomelatine was withdrawn in Korea and it is not available now due to issues with the system for management of insurance price, agomelatine was recommended as a first-line AD by the Korean experts in agreement with CANMAT 2009 ${ }^{18)}$ and CANMAT 2016, ${ }^{17)}$ whereas there had been no consensus regarding agomelatine in 2012. Although no clear difference in efficacy among ADs was apparent, ${ }^{24,25)}$ other factors including safety issues, clinical experience, and the rapidity of onset of $\mathrm{AD}$ action may underlie differences in preference among psychiatrists. ${ }^{26)}$

Influences on AD choice due to adverse effect, safety, and comorbid physical illness

Adverse effects. Comparisons of recommendations considering the side effects and safety of $A D$ and the im- 
pact of comorbid diabetes mellitus by American (APA, 2000), ${ }^{27)}$ Canadian 2007, ${ }^{28)}$ and English (NICE, 2009) ${ }^{21)}$ guidelines are fully subscribed to in KMAP-DD second revision. ${ }^{5)}$ Generally, the recommendations of the KMAP-DD third revision were similar to those of the KMAP-DD 2012. With the exception of concerns about their sexual side effects, sedation, Gl trouble, insomnia, and suicidality, the experts preferred SSRIs when considering issues related to safety, whereas they preferred bupropion when considering issues related to sexual dysfunction or sedation. Mirtazapine was preferred considering insomnia, Gl problems, or suicidality. Considering weight gain, fluoxetine was recommended as the first-line AD instead of bupropion $(50.8 \%$ in $2012,22.1 \%$ in this survey). Because bupropion may be related less with weight gain and more frequently with headache and dry mouth, the preference for bupropion to avoid weight gain has decreased. CANMAT 2016 ${ }^{17)}$ reviewed patients taking bupropion- $\mathrm{XL}$, and found that they had more headache and dry mouth, as often as $28 \%$ and $34 \%$, respectively, compared to other ADs.

Safety. 1) Cardiovascular effects: cardiovascular side effects are rare with SSRI use, and the expert group strongly preferred SSRIs rather than other ADs if cardiovascular effects are an issue. However, there have been reports of mild bradycardia in patients treated with fluoxetine, fluvoxamine, and paroxetine ${ }^{29)}$ and case reports of arrhythmia and syncope in response to treatment using SSRIs. ${ }^{30,31)}$ This suggests that clinical cardiac monitoring is necessary when using SSRIs, despite the fact that SSRIs are less associated with adverse cardiovascular events than are TCAs.

2) Suicidality: SSRIs are related to nearly twice the risk $(\mathrm{OR}, 1.92)$ of suicide and suicidal attempts among adolescents in observational studies ${ }^{32)}$ and in the US FDA direction that manufacturers of all AD revise their labeling as the result of an increase in suicidality among children and adolescents. The US FDA warning changed the target period from childhood and adolescence to young adulthood (18-24 years) during initial treatment. ${ }^{33)}$ Given these results and issues, mirtazapine rather than an SSRI was preferred by the Korean experts considering suicidality. Although the relation between AD and suicidality is not clear, ${ }^{28)}$ careful monitoring and assessment for suicidality should be undertaken at the beginning of $A D$ treatment, particularly in adolescent and young adults.
3) Comorbid physical illness: Epidemiological studies have shown that the prevalence of depression ranges from $9 \%$ to $43 \%$ among patients with physical illnesses, including diabetes mellitus, ${ }^{34)}$ cardiac disease, ${ }^{35)}$ cancer, ${ }^{36)}$ pain, ${ }^{37)}$ and stroke. ${ }^{38)}$ Although fluoxetine did not cause clinically significant changes in blood glucose levels in patients with diabetes mellitus or in thyroid hormone levels in patients with thyroid disease, ${ }^{39)}$ regular monitoring of the blood glucose and thyroid hormone levels in the depressed patient with diabetes mellitus or thyroid disease is recommended. ${ }^{40)}$ As SSRIs are metabolized in the liver, depressed patients with renal disease do not need to reduce $A D$ dosage ${ }^{41)}$ but depressed patients with liver disease do. $^{42)}$

\section{Treatment Duration with the Initial AD until Activation of Next Strategy (Switching to or Adding Other AD, etc.) due to Lack of Efficacy; Maintenance Treatment}

Treatment duration with initial AD until switching to another AD

Recommended treatment duration (2.92-6.41 weeks for mild-to-moderate, 2.82-6.05 weeks for severe episode) with the initial AD for non-psychotic depression was relatively shorter than in KMAP-DD 2012 (3.20-7.49 weeks). However, the initial AD treatment duration for psychotic depression was similar to that of KMAP-DD 2012 (No response, 2.3-4.7 weeks vs. 2.4-4.7 weeks in 2012; Partial response, 3.4-6.5 weeks vs. 3.4-6.9 weeks in 2012).

Recently, the clinical implications of early improvement, defined as $>20 \%$ to $30 \%$ reduction from baseline on a depression rating scale after 2 to 4 weeks of depression, have been emphasized. Evidence-based guidelines offer no recommendations on how long to maintain treatment with the initial AD in the expectation of seeing a response. Moreover, early improvement is correlated with later prognosis at 6 to 12 weeks and 2 to 4 weeks is considered the best duration for waiting for a response to the initial AD, based on low quality evidence. ${ }^{43)}$ Thus, failure to see an early improvement should cause the expert to apply a shorter waiting duration at the initial $A D$ treatment. 
Duration of maintenance treatment after remission: psychotic depression (Table 6)

The notion that the duration of the initial AD treatment depends on the number of recurring episodes of psychotic depression did not change over 2016, 2012, and 2006. For a first and second episode, experts recommended at least 5 to 20 months of treatment. For three or more episodes, $83.5 \%$ and $62.0 \%$ of experts recommended not to discontinue the AD or the AAP, respectively. CANMAT $2009^{18)}$ recommended 6 to 9 months as maintenance therapy, and 2 years or more for those with a risk factor for recurrence. Recent meta-analyses of 72 trials (1-12 months, $n=14,450$ ) and 34 trials (more than 12 months, $\mathrm{n}=7,253)$ found significant benefit of AD over placebo, ${ }^{44)}$ and results from 16 maintenance RCTs showed that the AD was superior to placebo in terms of recurrence (18\% vs. $37 \%$, respectively). ${ }^{45)}$

In summary, the duration of maintenance therapy for depressed patients depended on risk factors for recurrence, such as number of episodes, severity, psychiatric or physical comorbidity, and family history.

\section{Treatment Strategies for Persistent Depressive Disorder (Dysthymia), and Strategies Specific to Subtype or Specifiers Such as Mixed or Anxious Distress}

Treatment strategies for persistent depressive disorder

The initial strategy, AD monotherapy, was the same as that of KMAP-DD 2012. The difference was that the preference for bupropion was increased, moving it from a second- to a first-line drug. Among first-line drugs, the preference for SSRIs was higher than for SNRIs.

\section{Treatment strategies specific to subtype}

Melancholia: Little information about the most effective agents for the melancholic and atypical subtypes is available. $^{18)}$ Compared with KMAP-DD 2012, the preferences for escitalopram and venlafaxine were increased, which became the TOCs. Contrary to results of KMAP-DD 2012, the preference for bupropion for melancholia was decreased, to second-line. The APA 2010 describes ECT or pharmacotherapy as effective for the treatment of melancholia, and TCAs and SNRIs as more effective than SSRIs. These AD choices may reflect the core symptoms of melancholia, such as insomnia, anxiety, and psychomo- tor retardation. ${ }^{20)}$

Atypical features and seasonal pattern: Among first-line $A D s$, less sedative $A D s$ were selected. Paroxetine was the only SSRI recommended as a second-line AD, which may reflect concerns about the atypical symptoms, such as hypersomnia and psychomotor retardation. Because of the negative impact of drug-drug interactions, moclobemide was not selected as a first-line treatment in considering any subtype or any severity. Level- 1 evidence was found for the use of bupropion to prevent winter depressive disorder. ${ }^{46)}$ APA 2010 recommended pharmacotherapy and adjunctive phototherapy, and described bupropion SR as approved by the US FDA for MDD with seasonal pattern. ${ }^{20)}$

Treatment strategies for specifiers mixed feature and anxious distress (Table 6)

The survey on specifiers is a newly added set of questions in this revision. Initial strategies for "with anxious distress" were AD+AAP and AD monotherapy. However, among AAP and MS, quetiapine was only first-line, which indicated the cause treatment with AAP and combined AD. WFSBP 2013 recommended SSRI, venlafaxine or TCA for MDD patients with prominent anxiety symptoms due to potential benefits from those drugs. ${ }^{15)}$

Regarding MDD with mixed features, the first-line strategies were AD monotherapy and AD+AAP. In the survey for the Korean Medication Algorithm for Bipolar Disorder 2014, MS + AAP was the TOC for bipolar I disorder, with mixed features indicating the initial treatment strategy. ${ }^{47)}$ However, in this survey, MS + AAP were not included as options in the questionnaire, which need to be added in the next revision. CANMAT 2016 recommended monotherapy with lurasidone or ziprasidone owing to their efficacy compared with placebo. ${ }^{48,49)}$

\section{Treatment Strategies for Special Populations (Table 7)}

Treatment strategy for children and adolescents

DMDD is a new disorder introduced in DSM-5. The US National Institute of Mental Health offers severe mood dysregulation, and DSM-5 newly recognizes a disorder including two key symptoms, severe recurrent temper outbursts, and persistent irritability observable by others. DMDD symptoms are common in the child and adolescent, and the prevalence range is $2 \%$ to $5 \%{ }^{50,51)}$ 
Psychostimulant was excluded in this survey because the experts were asked to answer concerning DMDD in the absence of comorbid attention deficit/hyperactivity disorder (ADHD). There was no first-line strategy for DMDD and a lack of evidence, but some positive results have been reported with psychostimulants, with an ongoing divalproex sodium trial for ADHD and an adjunctive risperidone trial for tic disorder. The Korean experts cautiously recommended $\mathrm{AAP}, \mathrm{MS}$, or AD monotherapy, with $\mathrm{AD}+$ $\mathrm{AAP}$ as a second-line treatment plan. In treating tic disorder, aripiprazole is more favorable than risperidone in terms of side effects. ${ }^{52)}$ In this survey, aripiprazole was preferred.

The prevalence rates of depression in children and adolescents are $2 \%$ and 4 to $8 \%$, respectively. ${ }^{53)}$ Similar to the recommendations of KMAP-DD 2012, AD monotherapy was recommended as the TOC for mild-to-moderate, and AD monotherapy and AD+AAP were the TOC for psychotic severe episodes. Aripiprazole and risperidone were recommended as first-line AAPs for psychotic severe depression. However, it is not clear whether AD therapy is as effective in children and adolescents as it is in adults; furthermore, ADs may increase the risk of suicide or self-harm in adolescents ${ }^{18)}$ and may adversely affect young patients with bipolar disorder, particularly those who experienced the onset of depression before 24 years of age. ${ }^{54)}$ Thus, clinical guidelines for children and adolescents recommend that psychological approaches, including cognitive-behavioral therapy (CBT), interpersonal therapy (IPT), psychoeducation, emotional support, and personal psychotherapy need be considered before pharmacotherapy for uncomplicated mild depression, ${ }^{55,56)}$ and suggest that pharmacotherapy be reserved for patients with moderate or severe depressive episodes. ${ }^{53,57-59)}$

In this revision, the first-line ADs for children and adolescents with MDD were escitalopram and fluoxetine. A recent Cochrane review of 19 trials with subjects aged 6 to 18 years $(n=3,335)$ reported that fluoxetine was significantly more effective than placebo, that sertraline was significantly effective with a small effect size, and that paroxetine did not prove efficacious in this population. The authors recommended fluoxetine as the TOC for the child/adolescent with MDD. ${ }^{60,61)}$

Treatment strategy for elderly adults $\mathrm{AD}+\mathrm{AAP}$ as well as AD monotherapy were newly rec- ommended as first-line for non-psychotic severe depression. Aripiprazole and quetiapine were first-line AAP for elderly psychotic depression. Adjunctive aripiprazole with various ADs was found effective for elderly depression. ${ }^{62)}$ CANMAT 2016 recommended switching to quetiapine and aripiprazole or their combination for inadequate response to initial treatment in elderly depression. ${ }^{63)}$ SSRIs except paroxetine, recommended as second-line, became first-line ADs for the elderly. These results may reflect paroxetine's anticholinergic effect. ${ }^{64,65)}$

Despite lack of evidence in treating elderly depression, it is clear that certain factors should be considered. Aging has an effect on the incidence and treatment outcomes of depression; the drug-drug interactions resulting from polypharmacy and the various comorbid physical illnesses should be taken into account. ${ }^{66)}$ Because the vegetative symptoms of physical illnesses and impaired cognitive functioning may be misdiagnosed as symptoms of depression, ${ }^{67)}$ readjusting the dosage schedule or titration should be undertaken with caution.

Treatment strategy for women with PMDD or postpartum depression

As in the KMAP-DD 2012, the KMAP-DD 2017 recommends AD monotherapy as the TOC for PMDD and escitalopram is the TOC for PMDD; the other SSRIs, duloxetine, and desvenlafaxine were the recommended first-line drugs, consistent with previous studies. ${ }^{68)}$

The survey of MDD in pregnancy is a new section in this revision. MDD treatment should be chosen in light of a clear benefit-risk evaluation, taking into account possible harmful effects of the drugs on the fetus, potential malnutrition without MDD treatment, and risk of substance abuse including tobacco. ${ }^{69,70)}$ CANMAT 2016 recommends escitalopram and sertraline as second-line while CBT and IPT are recommended as first-line, with recommendation to be cautious of paroxetine and clomipramine, which may be related to cardiac malformations. ${ }^{71)}$

For postpartum depression, initial treatment strategies here are similar to those of KKAP-DD 2012, except that MS + AAP was recommended as first-line in 2012 for mild-to-moderate and psychotic severe episode, but are second-line in this revision.

ADs are the mainstays of the treatment of women with PMDD or postpartum depression. ${ }^{71)}$ However, preference for AAP has been increasing over revisions because the ef- 
ficacy of monotherapy and adjunction with AAP has been proven via various clinical trials. ${ }^{72-74)}$

The ADs with the least influence on postpartum and breast-feeding, such as escitalopram and sertraline ${ }^{75)}$ were also recommended by the Korean experts.

\section{Non-pharmacological Biological Therapy}

Consistent with KMAP-DD 2012, ECT was recommended as a first-line strategy for non-psychotic severe MDD with urgent suicidal risk, and as a second-line strategy for non-responders to AD monotherapy or combination therapy and combined with physical illness (Fig. 3). TMS was also a second strategy for non-responder on $A D$ combination therapy in severe episodes without psychotic features, and for non-responders to pharmacotherapy in moderate episodes. CANMAT 2016 recommended ECT as a second-line treatment for TRD with MDD, and rTMS as a first-line treatment based on the efficacy, tolerability, and safety. Most Korean experts consider ECT $(92.4 \%)$ and rTMS (86.0\%) good treatment strategies, but only $44.3 \%$ of experts have executed ECT, and only $31.6 \%$ have used rTMS ${ }^{76)}$ These results show that real practice in Korea is less accepting of ECT and rTMS. However, the executive committee recommended that ECT could be applied when depressed patients have potential suicidality or attempt. The frequencies of use of adjunctive complementary agents such as phototherapy, omega-3 nutritional therapy, and megavitamin with initial treatment drugs were $27.8 \%, 22.8 \%$, and $12.7 \%$, respectively. When used as adjunctives for TRD, the frequencies were $29.1 \%, 19.0 \%$, and $8.9 \%$, respectively.

Although the frequency of use of phototherapy was very low, CANMAT 2016 recommended monotherapy with phototherapy as a first-line treatment for seasonal MDD and mono- or adjunctive phototherapy as a second-line treatment for non-seasonal, mild-to-moderate MDD. ${ }^{77)}$ Its combination with complementary therapy is recommended as a second strategy for treatment-refractory patients in this revision and in CANMAT 2016. ${ }^{77)}$

\section{Advantages and Limitations of KMAP-DD Third Revision}

A major limitation of the present study is that it was based on the consensus of Korean experts rather than on evidence. As stated earlier, we believe that the expert consensus and the evidence-based guidelines are compli- mentary, not contradictory. Second, the review committee may have been too small $(n=144)$ to reach a valid consensus and to select a TOC. However, given that there are only 3,750 psychiatrists in Korea and given that the total membership of the KSAD is only 258, a sample of 144 psychiatrists may be sufficient. Finally, we did not explore psychosocial approaches, which should be addressed in a future study.

In summary, the pharmacological treatment strategy in KMAP-DD third revision was similar to that of KMAP-DD 2012; however, preference for the first-line use of AAPs was greater in 2012 than in 2006. Moreover, recommendations for specific ADs according to population, side effects, and safety issues reflect recent evidence.

To our knowledge, KMAP-DD third revision is the only expert's consensus guideline in the world that has been updated and revised in almost every 4-year period since 2002. We expect it to provide clinicians with useful information about the specific strategies and medications appropriate for treating patients with MDD.

\section{- Acknowledgments}

The present manuscript is a secondary publication of our group's papers which were already published in the Korean language. Though we have already published the papers in Korea, we decided to present and share the results with the experts who speak English according to conditions for acceptable secondary publications as stated in Uniform Requirements for Manuscripts Submitted to Biomedical Journals by International Committee of Medical Journal Editors.

This study was supported by the Korean Society for Affective Disorders and the Korean College of Neuropsychopharmacology. This research did not receive any specific grant from funding agencies in the commercial sector. The authors report no conflicts of interest in this work.

\section{REFERENCES}

1. Field M, Lohr KN. Guidelines for clinical practice: from development to use. Washington, D.C.:National Academy Press; 1992. p.32-35.

2. Seo JS, Song HR, Lee HB, Park YM, Hong JW, Kim W, et al. The Korean Medication Algorithm for Depressive Disorder: second revision. I Affect Disord 2014;167:312-321.

3. Woo YS, Rosenblat JD, Kakar R, Bahk WM, Mclntyre RS. Cognitive deficits as a mediator of poor occupational function 
in remitted major depressive disorder patients. Clin Psychopharmacol Neurosci 2016;14:1-16.

4. Lee MS, Lim SW, Cha JH, Chung SK, Kim KS, Kasper S, et al. The Korean Medication Algorithm for Major Depressive Disorder (KMA-MDD): report of the Korean society of depressive and bipolar disorders. Int I Psychiatry Clin Pract 2006; 10: 186-194.

5. Seo JS, Min KJ, Kim W, Seok JH, Bahk WM, Song HC, et al. Korean medication algorithm for depressive disorder 2006 (I). J Korean Neuropsychiatr Assoc 2007:46:453-460.

6. Fountoulakis KN, Young A, Yatham L, Grunze H, Vieta E, Blier $\mathrm{P}$, et al. The International College of Neuropsychopharmacology (CINP) treatment guidelines for bipolar disorder in adults (CINP-BD-2017), Part 1: background and methods of the development of guidelines. Int I Neuropsychopharmacol 2017; 20:98-120.

7. Lam RW, Kennedy SH, Parikh SV, MacQueen GM, Milev RV, Ravindran AV; CANMAT Depression Work Group. Canadian Network for Mood and Anxiety Treatments (CANMAT) 2016 clinical guidelines for the management of adults with major depressive disorder: introduction and methods. Can J Psychiatry 2016;61:506-509.

8. Möller HJ. The CINP bipolar algorithm project: Are everything clinical practice and guideline supported clinical decision making in contrast? In: 30th CINP World Congress of Neuropsychopharmacology; Jul 3-5, 2016; Seoul, Korea. S25-01.

9. American Psychiatric Association (APA). Practice guideline for the treatment of patients with major depressive disorder. 3rd ed. Washington, D.C.:APA;2010.

10. Komossa K, Depping AM, Gaudchau A, Kissling W, Leucht S. Second-generation antipsychotics for major depressive disorder and dysthymia. Cochrane Database Syst Rev 2010;(12):CD008121.

11. Spielmans Gl, Berman MI, Linardatos E, Rosenlicht NZ, Perry A, Tsai AC. Adjunctive atypical antipsychotic treatment for major depressive disorder: a meta-analysis of depression, quality of life, and safety outcomes. PLoS Med 2013;10: e1001403.

12. Wen XJ, Wang LM, Liu ZL, Huang A, Liu YY, Hu JY. Meta-analysis on the efficacy and tolerability of the augmentation of antidepressants with atypical antipsychotics in patients with major depressive disorder. Braz I Med Biol Res 2014:47:605-616.

13. Zhou X, Keitner Gl, Qin B, Ravindran AV, Bauer M, Del Giovane C, et al. Atypical antipsychotic augmentation for treatment-resistant depression: a systematic review and network meta-analysis. Int J Neuropsychopharmacol 2015;18: pyv060.

14. Suehs B, Argo TR, Bendele SD, Crismon ML, Trivedi MH, Kurian $\mathrm{B}$, et al. Texas medication algorithm project procedural manual: major depressive disorder algorithms. Austin, TX:Texas Department of State Health Services;2008.
15. Bauer M, Pfennig A, Severus E, Whybrow PC, Angst J, Möller HJ; World Federation of Societies of Biological Psychiatry. Task Force on Unipolar Depressive Disorders. World Federation of Societies of Biological Psychiatry (WFSBP) guidelines for biological treatment of unipolar depressive disorders, part 1: update 2013 on the acute and continuation treatment of unipolar depressive disorders. World J Biol Psychiatry 2013;14:334-385.

16. Nelson JC, Papakostas GI. Atypical antipsychotic augmentation in major depressive disorder: a meta-analysis of placebo-controlled randomized trials. Am J Psychiatry 2009;166: 980-991.

17. Kennedy SH, Lam RW, Mclntyre RS, Tourjman SV, Bhat V, Blier P, et al. Canadian Network for Mood and Anxiety Treatments (CANMAT) 2016 clinical guidelines for the management of adults with major depressive disorder: section 3. pharmacological treatments. Can J Psychiatry 2016;61:540-560.

18. Lam RW, Kennedy SH, Grigoriadis S, Mclntyre RS, Milev R, Ramasubbu R, et al. Canadian Network for Mood and Anxiety Treatments (CANMAT) clinical guidelines for the management of major depressive disorder in adults. III. Pharmacotherapy. J Affect Disord 2009; 117 Supp/ 1:S26-S43.

19. Wang HR, Bahk WM, Seo JS, Woo YS, Park YM, Jeong JH, et al. Korean Medication Algorithm for Depressive Disorder: comparisons with other treatment guidelines. Clin Psychopharmacol Neurosci 2017; 15:199-209.

20. American Psychiatric Association. Treatment of patients with major depression and practical guideline [Internet]. American Psychiatric Association; 2010 [cited at 2016 Nov 10]. Available from: http://psychiatryonline.org/guidelines.aspx.

21. National Institute for Health and Clinical Excellence (NICE). Quick reference guide. Depression: management of depression in primary and secondary care. London:NICE;2009.

22. Connolly KR, Thase ME. If at first you don't succeed: a review of the evidence for antidepressant augmentation, combination and switching strategies. Drugs 2011;71:43-64.

23. Cipriani A, Furukawa TA, Salanti G, Geddes JR, Higgins JP, Churchill R, et al. Comparative efficacy and acceptability of 12 new-generation antidepressants: a multiple-treatments meta-analysis. Lancet 2009;373:746-758.

24. Hansen RA, Gartlehner G, Lohr KN, Gaynes BN, Carey TS. Efficacy and safety of second-generation antidepressants in the treatment of major depressive disorder. Ann Intern Med 2005; 143:415-426.

25. Papakostas Gl, Fava M. A metaanalysis of clinical trials comparing moclobemide with selective serotonin reuptake inhibitors for the treatment of major depressive disorder. Can J Psychiatry 2006;51:783-790.

26. Watanabe N, Omori IM, Nakagawa A, Cipriani A, Barbui C, Churchill $\mathrm{R}$, et al. Mirtazapine versus other antidepressive agents for depression. Cochrane Database Syst Rev 2011; (12): CDO06528.

27. American Psychiatric Association. Practice guideline for the 
treatment of patients with major depressive disorder. 2nd ed. Washington, D.C.:American Psychiatric Association;2000.

28. Bauer M, Bschor T, Pfennig A, Whybrow PC, Angst J, Versiani $\mathrm{M}$, et al. World Federation of Societies of Biological Psychiatry (WFSBP) guidelines for biological treatment of unipolar depressive disorders in primary care. World I Biol Psychiatry 2007;8:67-104.

29. Pacher P, Ungvari Z, Nanasi PP, Furst S, Kecskemeti V. Speculations on difference between tricyclic and selective serotonin reuptake inhibitor antidepressants on their cardiac effects. Is there any? Curr Med Chem 1999;6:469-480.

30. Buff DD, Brenner R, Kirtane SS, Gilboa R. Dysrhythmia associated with fluoxetine treatment in an elderly patient with cardiac disease. J Clin Psychiatry 1991;52:174-176.

31. Friedman EH. Fluoxetine-induced bradycardia. J Clin Psychiatry 1991;52:477.

32. Barbui C, Esposito E, Cipriani A. Selective serotonin reuptake inhibitors and risk of suicide: a systematic review of observational studies. CMAJ 2009;180:291-297.

33. US Food and Drug Administration (FDA). Antidepressant use in children, adolescents, and adults [Internet]. Silver Spring, MD: US FDA; 2007 May 2 lupdated 2016 Apr 13; cited at 2013 Nov 20]. Available from: http://www.fda.gov/Drugs/ DrugSafety/InformationbyDrugClass/ucm096273.htm.

34. Anderson RJ, Freedland KE, Clouse RE, Lustman PJ. The prevalence of comorbid depression in adults with diabetes: a meta-analysis. Diabetes Care 2001;24:1069-1078.

35. Rudisch B, Nemeroff CB. Epidemiology of comorbid coronary artery disease and depression. Biol Psychiatry 2003;54:227240.

36. Raison $\mathrm{CL}$, Miller AH. When not enough is too much: the role of insufficient g/ucocorticoid signaling in the pathophysiology of stress-related disorders. Am J Psychiatry 2003;160: 1554-1565.

37. Ohayon MM, Schatzberg AF. Using chronic pain to predict depressive morbidity in the general population. Arch Gen Psychiatry 2003;60:39-47.

38. Whyte EM, Mulsant BH. Post stroke depression: epidemio/ogy, pathophysiology, and biological treatment. Biol Psychiatry 2002; 52:253-264.

39. Lustman PJ, Griffith LS, Clouse RE, Freedland KE, Eisen SA, Rubin EH, et al. Effects of nortriptyline on depression and glycemic control in diabetes: results of a double-blind, placebo-controlled trial. Psychosom Med 1997; 59:241-250.

40. Shelton RC, Winn S, Ekhatore N, Loosen PT. The effects of antidepressants on the thyroid axis in depression. Biol Psychiatry 1993;33:120-126.

41. de Carvalho GA, Bahls SC, Boeving A, Graf H. Effects of selective serotonin reuptake inhibitors on thyroid function in depressed patients with primary hypothyroidism or normal thyroid function. Thyroid 2009; 19:691-697.

42. Mandrioli R, Mercolini L, Saracino MA, Raggi MA. Selective serotonin reuptake inhibitors (SSRIS): therapeutic drug mon- itoring and pharmacological interactions. Curr Med Chem 2012;19:1846-1863.

43. Nakajima S, Uchida H, Suzuki T, Watanabe K, Hirano J, Yagihashi $\mathrm{T}$, et al. Is switching antidepressants following early nonresponse more beneficial in acute-phase treatment of depression?: a randomized open-label trial. Prog Neuropsychopharmacol Biol Psychiatry 2011,35:1983-1989.

44. Sim K, Lau WK, Sim J, Sum MY, Baldessarini RJ. Prevention of relapse and recurrence in adults with major depressive disorder: systematic review and meta-analyses of controlled trials. Int J Neuropsychopharmacol 2015;19:pyv076.

45. Baldessarini RJ, Lau WK, Sim J, Sum MY, Sim K. Duration of initial antidepressant treatment and subsequent relapse of major depression. J Clin Psychopharmacol 2015;35:75-76.

46. Modell JG, Rosenthal NE, Harriett AE, Krishen A, Asgharian A, Foster VJ, et al. Seasonal affective disorder and its prevention by anticipatory treatment with bupropion XL. Biol Psychiatry 2005;58:658-667.

47. Seo JS, Bahk WM, Lee JG, Woo YS, Jeong JH, Wang HR, et al. Korean Medication Algorithm for Bipolar Disorder 2014: depressive episode. Korean J Psychopharmacol 2014;25:68-78.

48. Patkar A, Gilmer W, Pae CU, Vöhringer PA, Ziffra M, Pirok E, et al. A 6 week randomized double-blind placebo-controlled trial of ziprasidone for the acute depressive mixed state. PLoS One 2012;7:e34757.

49. Suppes T, Silva R, Cucchiaro J, Mao Y, Targum S, Streicher C, et al. Lurasidone for the treatment of major depressive disorder with mixed features: a randomized, double-blind, placebo-controlled study. Am J Psychiatry 2016;173:400-407.

50. American Psychiatric Association. Diagnostic and statistical manual of mental disorders fifth edition (DSM 5). Washington, D.C.:American Psychiatric Publishing;2013.

51. Baweja R, Mayes SD, Hameed U, Waxmonsky JG. Disruptive mood dysregulation disorder: current insights. Neuropsychiatr Dis Treat 2016;12:2115-2124.

52. Yoo HK, Lee JS, Paik KW, Choi SH, Yoon SJ, Kim JE, et al. Open-label study comparing the efficacy and tolerability of aripiprazole and haloperidol in the treatment of pediatric tic disorders. Eur Child AdolesC Psychiatry 2011;20:127-135.

53. Birmaher B, Brent D; AACAP Work Group on Quality Issues, Bernet W, Bukstein O, Walter $\mathrm{H}$, Benson RS, et al. Practice parameter for the assessment and treatment of children and adolescents with depressive disorders. I Am Acad Child Adolesc Psychiatry 2007;46:1503-1526.

54. Ghaemi SN, Ko JY, Goodwin FK. "Cade's disease” and beyond: misdiagnosis, antidepressant use, and a proposed definition for bipolar spectrum disorder. Can I Psychiatry 2002; 47:125-134.

55. Weisz JR, McCarty CA, Valeri SM. Effects of psychotherapy for depression in children and adolescents: a meta-analysis. Psychol Bull 2006;132:132-149.

56. Klein JB, Jacobs RH, Reinecke MA. Cognitive-behavioral therapy for adolescent depression: a meta-analytic investigation 
of changes in effect-size estimates. I Am Acad Child Adolesc Psychiatry 2007;46:1403-1413.

57. Cheung AH, Zuckerbrot RA, Jensen PS, Ghalib K, Laraque D, Stein RE; GLAD-PC Steering Group. Guidelines for Adolescent Depression in Primary Care (GLAD-PC): II. Treatment and ongoing management. Pediatrics 2007;120:e1313-e1326.

58. Hughes CW, Emslie GJ, Crismon ML, Posner K, Birmaher B, Ryan N, et al. Texas children's medication algorithm project: update from Texas Consensus Conference Panel on Medication Treatment of Childhood Major Depressive Disorder. J Am Acad Child Adolesc Psychiatry 2007;46:667-686.

59. Zuckerbrot RA, Cheung AH, Jensen PS, Stein RE, Laraque D; GLAD-PC Steering Group. Guidelines for Adolescent Depression in Primary Care (GLAD-PC): I. Identification, assessment, and initial management. Pediatrics 2007;120:e1299e1312.

60. Hetrick SE, McKenzie JE, Cox GR, Simmons MB, Merry SN. Newer generation antidepressants for depressive disorders in children and adolescents. Cochrane Database Syst Rev 2012;11:CD004851.

61. Cipriani A, Zhou X, Del Giovane C, Hetrick SE, Qin B, Whittington $\mathrm{C}$, et al. Comparative efficacy and tolerability of antidepressants for major depressive disorder in children and adolescents: a network meta-analysis. Lancet 2016;388:881890.

62. Steffens DC, Nelson JC, Eudicone JM, Andersson C, Yang H, Tran QV, et al. Efficacy and safety of adjunctive aripiprazole in major depressive disorder in older patients: a pooled subpopulation analysis. Int J Geriatr Psychiatry 2011;26:564572.

63. MacQueen GM, Frey BN, Ismail Z, Jaworska N, Steiner M, Lieshout RJ, et al. Canadian Network for Mood and Anxiety Treatments (CANMAT) 2016 clinical guidelines for the management of adults with major depressive disorder: section 6. special populations: youth, women, and the elderly. Can J Psychiatry 2016;61:588-603.

64. Owens MJ, Morgan WN, Plott SJ, Nemeroff CB. Neurotransmitter receptor and transporter binding profile of antidepressants and their metabolites. J Pharmacol Exp Ther 1997;283:13051322.

65. Sanchez C, Reines EH, Montgomery SA. A comparative review of escitalopram, paroxetine, and sertraline: Are they all alike? Int Clin Psychopharmacol 2014;29:185-196.

66. Alexopoulos GS, Katz IR, Reynolds CF 3rd, Carpenter D, Docherty JP; Expert Consensus Panel for Pharmacotherapy of Depressive Disorders in Older Patients. The expert consensus guideline series. Pharmacotherapy of depressive disorders in older patients. Postgrad Med 2001; Spec No Pharmacotherapy:1-86.
67. Kim JM, Hong JP, Kim SD, Kang HJ, Lee YS. Development of a Korean version of the Perceived Deficits QuestionnaireDepression for patients with major depressive disorder. Clin Psychopharmacol Neurosci 2016;14:26-32.

68. Biggs WS, Demuth RH. Premenstrual syndrome and premenstrual dysphoric disorder. Am Fam Physician 2011;84: 918-924.

69. Le Strat Y, Dubertret C, Le Foll B. Child marriage in the United States and its association with mental health in women. Pediatrics 2011;128:524-530.

70. Zuckerman B, Amaro H, Bauchner H, Cabral H. Depressive symptoms during pregnancy: relationship to poor health behaviors. Am J Obstet Gynecol 1989;160:1107-1111.

71. Ng RC, Hirata CK, Yeung W, Haller E, Finley PR. Pharmacologic treatment for postpartum depression: a systematic review. Pharmacotherapy 2010;30:928-941.

72. Thase ME, Corya SA, Osuntokun O, Case M, Henley DB, Sanger TM, et al. A randomized, double-blind comparison of olanzapine/fluoxetine combination, olanzapine, and fluoxetine in treatment-resistant major depressive disorder. J Clin Psychiatry 2007;68:224-236.

73. Berman RM, Fava M, Thase ME, Trivedi MH, Swanink R, McQuade RD, et al. Aripiprazole augmentation in major depressive disorder: a double-blind, placebo-controlled study in patients with inadequate response to antidepressants. CNS Spectr 2009; 14:197-206.

74. El-Khalili N, Joyce M, Atkinson S, Buynak RJ, Datto C, Lindgren $\mathrm{P}$, et al. Extended-release quetiapine fumarate (quetiapine $X R$ ) as adjunctive therapy in major depressive disorder (MDD) in patients with an inadequate response to ongoing antidepressant treatment: a multicentre, randomized, double-blind, placebo-controlled study. Int I Neuropsychopharmacol 2010;13:917-932.

75. Molyneaux E, Howard LM, McGeown HR, Karia AM, Trevillion K. Antidepressant treatment for postnatal depression. Issues Ment Health Nurs 2017;38:188-190.

76. Milev RV, Giacobbe P, Kennedy SH, Blumberger DM, Daskalakis ZJ, Downar J, et al. Canadian Network for Mood and Anxiety Treatments (CANMAT) 2016 clinical guidelines for the management of adults with major depressive disorder: section 4. neurostimulation treatments. Can J Psychiatry 2016;61:561-575.

77. Ravindran AV, Balneaves LG, Faulkner G, Ortiz A, McIntosh D, Morehouse RL, et al. Canadian Network for Mood and Anxiety Treatments (CANMAT) 2016 clinical guidelines for the management of adults with major depressive disorder: section 5. complementary and alternative medicine treatments. Can J Psychiatry 2016;61:576-587. 